Distr.: Limited

12 December 2015

Russian

Original: English

\title{
Конференция Сторон
}

Двадцать первая сессия

Париж, 30 ноября - 11 декабря 2015 года

Пункт 4 b) повестки дня

Дурбанская платформа для более активных

действий (решение 1/CP.17)

Принятие протокола, иного правового акта

или имеющего юридическую силу согласованного

итогового документа согласно Конвенции,

применимого ко всем Сторонам

\section{Принятие Парижского соглашения}

\section{Предложение Председателя}

\section{Проект решения -/CP.21}

Конференичия Сторон,

cсылаясь на решение 1/СР.17 об учреждении Специальной рабочей группы по Дурбанской платформе для более активных действий,

также ссылаясь на статьи 2, 3 и 4 Конвенции,

далее ссылаясь на соответствующие решения Конференции Сторон, включая решения 1/СР.16, 2/СР.18, 1/СР.19 и 1/СР.20,

приветствуя принятие резолюции A/RES/70/1 Генеральной Ассамблеи Opганизации Объединенных Наций «Преобразование нашего мира: Повестка дня в области устойчивого развития на период до 2030 года», в частности изложенную в ней цель 13, принятие Аддис-Абебской программы действий третьей Международной конференции по финансированию развития и принятие Сендайской рамочной программы по снижению риска бедствий,

признавая, что изменение климата представляет безотлагательную и потенциально необратимую угрозу для человеческих обществ и планеты и поэтому требует как можно более широкого сотрудничества всех стран и их участия в эффективном и надлежащем международном реагировании в целях ускорения сокращения глобальных выбросов парниковых газов,

также признавая, что для достижения глобальной цели Конвенции потребуются глубокие сокращения глобальных выбросов, и особо отмечая необходимость срочно решить проблемы, связанные с изменением климата, 
подтверждая, что изменение климата является общей озабоченностью человечества, Стороны должны, при осуществлении действий в целях решения проблем, связанных с изменением климата, уважать, поощрять и принимать во внимание свои соответствующие обязательства в области прав человека, право на здоровье, права коренных народов, местных общин, мигрантов, детей, инвалидов и лиц, находящихся в уязвимом положении, и право на развитие, а также гендерное равенство, расширение возможностей женщин и межпоколенческую справедливость,

также подтверждая конкретные потребности и обеспокоенности Сторон, являющихся развивающимися странами, в связи с воздействием осуществления мер реагирования и ссылаясь в этом отношении на решения 5/CР.7, 1/СР.10, 1/СР.16 и 8/CР.17,

особо отмечая с серьезной обеспокоенностью безотлагательную необходимость преодоления значительного разрыва между совокупным эффектом принятых Сторонами обязательств по предотвращению изменения климата с точки зрения сокращения глобальных ежегодных выбросов парниковых газов к 2020 году и траекториями совокупных выбросов соразмерно целям удержания прироста глобальной средней температуры намного ниже $2{ }^{\circ} \mathrm{C}$ сверх доиндустриальных уровней и продолжения усилий по ограничению роста температуры до $1,5{ }^{\circ} \mathrm{C}$,

также особо отмечая, что повышение амбициозности в период до 2020 года может заложить прочную основу для повышения амбициозности в период после 2020 года,

подчеркивая крайнюю необходимость ускорения осуществления Конвенции и Киотского протокола к ней, с тем чтобы повысить амбициозность в период до 2020 года,

признавая безотлагательную необходимость расширения предоставления финансовой, технологической поддержки и поддержки в области укрепления потенциала Сторонами, являющимися развитыми странами, предсказуемым образом, с тем чтобы Стороны, являющиеся развивающимися странами, могли активизировать действия в период до 2020 года,

особо отмечая долгосрочные преимущества амбициозных и своевременных действий, включая значительные сокращения затрат, сопряженных с будущими усилиями по предотвращению изменения климата и адаптации,

подтверждая необходимость поощрения всеобщего доступа к устойчивой энергии в развивающихся странах, в частности в Африке, посредством более действенного освоения возобновляемых источников энергии,

соглашаясь поддерживать и поощрять региональное и международное сотрудничество в целях мобилизации более активных и амбициозных действий в интересах климата всеми Сторонами и заинтересованными субъектами, не являющимися Сторонами, включая гражданское общество, частный сектор, финансовые учреждения, городские и другие субнациональные власти, местные общины и коренные народы,

\section{I. Принятие}

1. постановляет принять Парижское соглашение согласно Рамочной конвенции Организации Объединенных Наций об изменении климата (далее упоминается как «Соглашение»), содержащееся в приложении; 
2. просит Генерального секретаря Организации Объединенных Наций взять на себя функции Депозитария Соглашения и открыть его для подписания в НьюЙорке, Соединенные Штаты Америки, с 22 апреля 2016 года по 21 апреля 2017 года;

3. предлагает Генеральному секретарю созвать церемонию высокого уровня для подписания этого Соглашения 22 апреля 2016 года;

4. также предлагает всем Сторонам Конвенции подписать это Соглашение в ходе церемонии, которая будет созвана Генеральным секретарем, или как только они смогут сделать это, и как можно скорее сдать на хранение свои соответствующие документы о ратификации, принятии, одобрении или присоединении, в зависимости от обстоятельств;

5. признает, что Стороны Конвенции могут на временной основе применять все положения Соглашения до его вступления в силу, и просит Стороны представить Депозитарию уведомление о любом таком временном применении;

6. отмечает завершение работы Специальной рабочей группы по Дурбанской платформе для более активных действий в соответствии с пунктом 4 решения 1/CР.17;

7. постановляет учредить Специальную рабочую группу по Парижскому соглашению в рамках такой же договоренности mutatis mutandis, как и в отношении выборов должностных лиц Бюро Специальной рабочей группы по Дурбанской платформе для более активных действий ${ }^{1}$;

8. также постановляет, что Специальная рабочая группа по Парижскому соглашению проведет подготовительную работу для вступления Соглашения в силу и для созыва первой сессии Конференции Сторон, действующей в качестве совещания Сторон Парижского соглашения;

9. далее постановляет контролировать осуществление программы работы, являющейся результатом соответствующих просьб, содержащихся в настоящем решении;

10. просит Специальную рабочую группу по Парижскому соглашению регулярно представлять Конференции Сторон доклады о прогрессе в ее работе и завершить свою работу до первой сессии Конференции Сторон, действующей в качестве совещания Сторон Парижского соглашения;

11. постановляет, что Специальная рабочая группа по Парижскому соглашению будет проводить свои сессии, начиная с 2016 года, одновременно с сессиями вспомогательных органов по Конвенции и будет подготавливать проекты решений, которые будут рекомендоваться Конференции Сторон, действующей в качестве совещания Сторон Парижского соглашения, через Конференцию Сторон для рассмотрения и принятия на ее первой сессии;

\section{II. Предполагаемые определяемые на национальном уровне вклады}

12. приветствует предполагаемые определяемые на национальном уровне вклады, которые были сообщены Сторонами в соответствии с пунктом 2 b) peшения 1/CР.19;

13. вновь повторяет свой призыв ко всем Сторонам, которые еще не сделали этого, сообщить в секретариат свои предполагаемые определяемые на нацио-

\footnotetext{
${ }^{1}$ Одобрено решением 2/СР.18, пункт 2.
} 
нальном уровне вклады, направленные на достижение цели Конвенции, изложенной в ее статье 2, как можно скорее и заблаговременно до двадцать второй сессии Конференции Сторон (ноябрь 2016 года) и таким образом, чтобы способствовать ясности, транспарентности и пониманию предполагаемых определяемых на национальном уровне вкладов;

14. просит секретариат продолжать публиковать предполагаемые определяемые на национальном уровне вклады, сообщаемые Сторонами, на веб-сайте РКИКООН;

15. вновь повторяет свой призыв к Сторонам, являющимся развитыми странами, оперативным органам Финансового механизма и любым другим организациям, которые способны сделать это, предоставлять поддержку для подготовки и сообщения предполагаемых определяемых на национальном уровне вкладов Сторон, которые могут нуждаться в такой поддержке;

16. принимает к сведению обобщающий доклад о совокупном воздействии предполагаемых определяемых на национальном уровне вкладов, сообщенных Сторонами до 1 октября 2015 года, который содержится в документе FCCC/CP/2015/7;

17. с озабоченностью отмечает, что оценочные совокупные уровни выбросов парниковых газов в 2025 и 2030 годах в результате предполагаемых определяемых на национальном уровне вкладов не укладываются в рамки наименее затратных сценариев « $2{ }^{\circ} \mathrm{C»,} \mathrm{а} \mathrm{приводят} \mathrm{к} \mathrm{прогнозируемому} \mathrm{уровню} \mathrm{в} \mathrm{размере}$ 55 гигатонн в 2030 году, и также отмечает, что потребуются значительно более масштабные усилия по сокращению выбросов, чем усилия, связанные с предполагаемыми определяемыми на национальном уровне вкладами, чтобы удержать прирост глобальной средней температуры ниже $2{ }^{\circ} \mathrm{C}$ сверх доиндустриальных уровней за счет сокращения выбросов до 40 гигатонн или до $1,5^{\circ} \mathrm{C}$ сверх доиндустриальных уровней за счет сокращения до уровня, который будет установлен в специальном докладе, упомянутом в пункте 21 ниже;

18. также отмечает в этом контексте потребности в области адаптации, указанные многими Сторонами, являющимися развивающимися странами, в их предполагаемых определяемых на национальном уровне вкладах;

19. просит секретариат обновить обобщающий доклад, упомянутый в пункте 16 выше, с тем чтобы охватить всю информацию, содержащуюся в предполагаемых определяемых на национальном уровне вкладах, сообщенных Сторонами во исполнение решения 1/СР.20 до 4 апреля 2016 года, и представить его до 2 мая 2016 года;

20. постановляет созвать стимулирующий диалог между Сторонами в 2018 году для подведения итогов коллективных усилий Сторон в связи с прогрессом в деле достижения долгосрочной цели, упомянутой в пункте 1 статьи 4 Соглашения, и создания информационной основы для подготовки предполагаемых определяемых на национальном уровне вкладов во исполнение пункта 8 статьи 4 Соглашения;

21. предлагает Межправительственной группе экспертов по изменению климата представить в 2018 году специальный доклад о воздействиях глобального потепления на $1,5^{\circ} \mathrm{C}$ сверх доиндустриальных уровней и о соответствующих траекториях глобальных выбросов парниковых газов; 


\title{
III. Решения, касающиеся вступления в силу Соглашения
}

\author{
Предотвращение изменения климата
}

22. предлагает Сторонам представить свой первый определяемый на национальном уровне вклад не позднее направления Стороной своего соответствующего документа о ратификации, одобрении Парижского соглашения или присоединении к нему. Если Сторона представила предполагаемый определяемый на национальном уровне вклад до вступления Соглашения в силу, то будет считаться, что данная Сторона выполнила настоящее положение, если эта Сторона не примет иное решение;

23. настоятельно предлагает тем Сторонам, определяемый на национальном уровне вклад которых в соответствии с решением 1/CР.20 содержит временной график до 2025 года, представить или обновить до 2020 года эти вклады и делать это раз в пять лет в последующий период в соответствии с пунктом 9 статьи 4 Соглашения;

24. предлагает тем Сторонам, определяемый на национальном уровне вклад которых в соответствии с решением 1/СР.20 содержит временной график до 2030 года, представить или обновить до 2020 года эти вклады и делать это раз в пять лет в последующий период в соответствии с пунктом 9 статьи 4 Соглашения;

25. постановляет, что Стороны представляют в секретариат свои определяемые на национальном уровне вклады, упоминаемые в статье 4 Соглашения, не позднее чем за 9-12 месяцев до начала соответствующего совещания Конференции Сторон, действующей в качестве совещания Сторон Парижского соглашения, для окончательной доработки в целях содействия ясности, транспарентности и пониманию этих вкладов, в том числе с помощью обобщающего доклада, подготовленного секретариатом;

26. просит Специальную рабочую группу по Парижскому соглашению разработать дополнительные руководящие указания по характеристикам определяемых на национальном уровне вкладов для рассмотрения и принятия Конференцией Сторон, действующей в качестве совещания Сторон Парижского соглашения, на ее первой сессии;

27. постановляет, что информация, которая сообщается Сторонами, представляющими свои определяемые на национальном уровне вклады для содействия ясности, транспарентности и пониманию, может включать в надлежащих случаях, помимо прочего, поддающуюся количественной оценке информацию об исходной точке (включая, в соответствующих случаях, базовый год); временны́е рамки и/или периоды осуществления, масштаб и сферу охвата, процессы планирования, допущения и методологические подходы, в том числе для оценки и учета антропогенных выбросов и, в соответствующих случаях, абсорбции парниковых газов, а также информацию о том, почему Сторона считает, что ее определяемый на национальном уровне вклад является справедливым и амбициозным в свете ее национальных условий, и как он способствует достижению цели Конвенции, изложенной в ее статье 2 ;

28. просит Специальную рабочую группу по Парижскому соглашению разработать дальнейшие руководящие указания в отношении информации, которую должны предоставлять Стороны для содействия ясности, транспарентности и пониманию определяемых на национальном уровне вкладов, для рассмотрения и принятия Конференцией Сторон, действующей в качестве совещания Сторон Парижского соглашения, на ее первой сессии; 
29. также просит Вспомогательный орган по осуществлению разработать условия и процедуры для функционирования и использования публичного реестра, упомянутого в пункте 12 статьи 4 Соглашения, для рассмотрения и принятия Конференцией Сторон, действующей в качестве совещания Сторон Парижского соглашения, на ее первой сессии;

30. далее просит секретариат обеспечить наличие временного публичного реестра в первой половине 2016 года для регистрации определяемых на национальном уровне вкладов, представленных в соответствии со статьей 4 Соглашения до принятия Конференцией Сторон, действующей в качестве совещания Сторон Парижского соглашения, условий и процедур, упомянутых в пункте 29 выше;

31. просит Специальную рабочую группу по Парижскому соглашению разработать, опираясь на подходы, предусмотренные в Конвенции и ее соответствующих правовых инструментах, в надлежащих случаях, руководящие указания для обеспечения отчетности по определяемым на национальном уровне вкладам Сторон, как это указано в пункте 13 статьи 4 Соглашения, для рассмотрения и принятия Конференцией Сторон, действующей в качестве совещания Сторон Парижского соглашения, на ее первой сессии, которые обеспечивают, что:

a) Стороны представляют отчетность по антропогенным выбросам и абсорбции в соответствии с общими методологиями и метриками, оцененными Международной группой экспертов по изменению климата и утвержденными Конференцией Сторон, действующей в качестве совещания Сторон Парижского соглашения;

b) Стороны обеспечивают методологическую последовательность, в том числе в отношении исходных условий, между сообщением и осуществлением определяемых на национальном уровне вкладов;

c) Стороны стремятся включить все категории антропогенных выбросов или абсорбции в свои определяемые на национальном уровне вклады и, после того как источник, поглотитель или вид деятельности был учтен, продолжать включать его;

d) Стороны представляют пояснения в отношении того, почему какиелибо категории антропогенных выбросов или абсорбции были исключены;

32. постановляет, что Стороны применяют руководящие указания, упомянутые в пункте 31 выше, ко второму и последующим определяемым на национальном уровне вкладам и что Стороны могут принять решение о применении таких руководящих указаний к их первому определяемому на национальном уровне вкладу;

33. также постановляет, что под руководством вспомогательных органов продолжает созываться Форум по вопросу о воздействии процесса осуществления мер реагирования, который обслуживает Соглашение;

34. далее постановляет, что Вспомогательный орган для консультирования по научным и техническим аспектам и Вспомогательный орган по осуществлению рекомендуют Конференции Сторон, действующей в качестве совещания Сторон Парижского соглашения, для рассмотрения и принятия на ее первой сессии условия, программу работы и функции Форума по вопросу о воздействии процесса осуществления мер реагирования с целью решения проблемы последствий осуществления мер реагирования в соответствии с Соглашением путем укрепления сотрудничества между Сторонами в вопросах понимания воздействий мер по предотвращению изменения климата в рамках Соглашения и посредством улуч- 
шения обмена информацией, опытом и передовой практикой между Сторонами в интересах повышения их устойчивости к этим воздействиям;

35. постановляет, что руководящие указания в соответствии с пунктом 31 выше должны обеспечивать недопущение двойного подсчета на основе соответствующей корректировки обеими Сторонами антропогенных выбросов из источников и/или абсорбции поглотителями, охваченных их определяемыми на национальном уровне вкладами, в соответствии с Соглашением;

36. предлагает Сторонам представить до 2020 года в секретариат рассчитанные на середину века стратегии долгосрочного развития с низким уровнем выбросов парниковых газов в соответствии с пунктом 19 статьи 4 Соглашения и просит секретариат опубликовать на веб-сайте РКИКООН представленные Сторонами стратегии долгосрочного развития с низким уровнем выбросов парниковых газов;

37. просит Вспомогательный орган для консультирования по научным и техническим аспектам разработать и рекомендовать руководящие указания, упомянутые в пункте 2 статьи 6 Соглашения, для принятия Конференцией Сторон, действующей в качестве совещания Сторон Парижского соглашения, на ее первой сессии, в том числе руководящие указания, обеспечивающие недопущение двойного подсчета на основе соответствующей корректировки Сторонами как антропогенных выбросов из источников, так и абсорбции поглотителями, охваченных их определяемыми на национальном уровне вкладами, в соответствии с Соглашением;

38. рекомендует Конференции Сторон, действующей в качестве совещания Сторон Парижского соглашения, принять правила, условия и процедуры для механизма, созданного в соответствии с пунктом 4 статьи 6 Соглашения, на основе:

а) добровольного участия, санкционированного каждой участвующей Стороной;

b) реальных, поддающихся измерению и долгосрочных преимуществ, связанных с предотвращением изменения климата;

c) конкретных масштабов деятельности;

d) сокращения выбросов, которые являются дополнительными к тем, которые имели бы место в ином случае;

е) проверки и сертификации сокращений выбросов в результате деятельности по предотвращению изменения климата, осуществляемой назначенными оперативными органами;

f) накопленного опыта и извлеченных уроков, которые стали результатами функционирования существующих механизмов и применения подходов, принятых согласно Конвенции и связанным с ней правовым документам;

39. просит Вспомогательный орган для консультирования по научным и техническим аспектам разработать и рекомендовать правила, условия и процедуры для механизма, упомянутого в пункте 38 выше, для рассмотрения и принятия Конференцией Стороной, действующей в качестве совещания Сторон Парижского соглашения, на ее первой сессии;

40. также просит Вспомогательный орган для консультирования по научным и техническим аспектам осуществить программу работы в рамках нерыночных подходов к устойчивому развитию, упомянутых в пункте 8 статьи 6 Соглашения, с целью рассмотреть, как укрепить связи и достичь синергии между, в частности, предотвращением изменения климата, адаптацией, финансированием, передачей 
технологий и укреплением потенциала и как содействовать внедрению и координации нерыночных подходов;

41. далее просит Вспомогательный орган для консультирования по научным и техническим аспектам рекомендовать проект решения о программе работы, упомянутой в пункте 40 выше, принимая во внимание мнения Сторон, для рассмотрения и принятия Конференцией Сторон, действующей в качестве совещания Сторон Парижского соглашения, на ее первой сессии;

\section{Адаптацчия}

42. просит Комитет по адаптации и Группу экспертов по наименее развитым странам совместно разработать условия для признания усилий по адаптации Сторон, являющихся развивающимися странами, как это упомянуто в пункте 3 статьи 7 Соглашения, и подготовить рекомендации для рассмотрения и принятия Конференцией Стороной, действующей в качестве совещания Сторон Парижского соглашения, на ее первой сессии;

43. также просит Комитет по адаптации с учетом его мандата и его второго трехлетнего плана работы и с целью подготовить рекомендации для рассмотрения и принятия Конференцией Сторон, действующей в качестве совещания Сторон Парижского соглашения, на ее первой сессии:

a) провести в 2017 году обзор работы относящихся к адаптации институциональных механизмов в соответствии с Конвенцией для выявления путей повышения слаженности их работы, когда это необходимо, в целях адекватного реагирования на потребности Сторон;

b) рассмотреть методологии для оценки потребностей в адаптации в целях оказания помощи развивающимся странам, не накладывая на них ненужного бремени;

44. призывает все соответствующие учреждения Организации Объединенных Наций и международные, региональные и национальные финансовые институты представлять Сторонам через секретариат информацию о том, каким образом их программы помощи в целях развития и финансирования борьбы с изменением климата включают меры по защите от изменения климата и по повышению сопротивляемости к изменению климата;

45. просит Стороны укреплять региональное сотрудничество в области адаптации и, когда это необходимо, создавать региональные центры и сети, в особенности в развивающихся странах, с учетом пункта 13 решения 1/CР.16;

46. также просит Комитет по адаптации и Группу экспертов по наименее развитым странам в сотрудничестве с Постоянным комитетом по финансам и другими соответствующими учреждениями разработать методологии и вынести рекомендации для рассмотрения и принятия Конференцией Сторон, действующей в качестве совещания Сторон Парижского соглашения, на ее первой сессии относительно:

a) принятия необходимых мер для содействия мобилизации поддержки в интересах адаптации в развивающихся странах в контексте ограничения роста глобальной средней температуры, упомянутого в статье 2 Соглашения;

b) проведения обзора достаточности и эффективности адаптации и поддержки, упомянутой в пункте 14 с) статьи 7 Соглашения;

47. далее просит Зеленый климатический фонд ускорить предоставление поддержки наименее развитым странам и другим Сторонам, являющимся развивающимися странами, в формулировании национальных планов по адаптации, со- 
гласно решениям 1/СР.16 и 5/СР.17, и в последующем осуществлении политики, проектов и программ, определенных ими;

Потери и ущерб

48. принимает решение о продолжении функционирования Варшавского международного механизма по потерям и ущербу в результате воздействий изменения климата после проведения обзора в 2016 году;

49. просит Исполнительный комитет Варшавского международного механизма учредить информационно-координационный центр для передачи рисков, который бы служил хранилищем для информации о страховании и передаче рисков с целью содействовать усилиям Сторон по разработке и осуществлению всеобъемлющих стратегий управления рисками;

50. также просит Исполнительный комитет Варшавского международного механизма учредить в соответствии со своими процедурами и мандатом целевую группу, которая бы дополняла деятельность существующих органов и групп экспертов в рамках Конвенции, включая Комитет по адаптации и Группу экспертов по наименее развитым странам, равно как и соответствующих организаций и экспертных органов, действующих вне рамок Конвенции, использовала результаты их работы и привлекала их к участию, если это уместно, с целью подготовки рекомендаций в отношении всесторонних подходов к предотвращению, сведению к минимуму и решению проблемы перемещения людей, связанного с негативными последствиями изменения климата;

51. далее просит Исполнительный комитет Варшавского международного механизма начать на его следующем совещании работу, связанную с реализацией положений, содержащихся в пунктах 49 и 50 выше, и сообщить о достигнутом прогрессе в своем ежегодном докладе;

52. соглашается с тем, что статья 8 Соглашения не влечет за собой и не служит основанием для какой-либо ответственности или компенсации;

\section{Финансы}

53. постановляет, что при осуществлении Соглашения финансовые ресурсы, предоставляемые развивающимся странам, должны содействовать активизации осуществления их политики, стратегий, норм регулирования, планов действий и мер по борьбе с изменением климата в отношении как предотвращения изменения климата, так и адаптации, с тем чтобы способствовать достижению цели Соглашения, определенной в статье 2;

54. далее постановляет, что в соответствии с пунктом 3 статьи 9 Соглашения развитые страны намерены продолжать реализацию своей существующей совместной цели по мобилизации ресурсов до 2025 года в контексте значимых действий по предотвращению изменения климата и транспарентности в области осуществления; до 2025 года Конференция Сторон, действующая в качестве совещания Сторон Парижского соглашения, установит новую коллективную и выраженную количественно цель начиная с минимального уровня в 100 млрд. долл. США в год с учетом потребностей и приоритетов развивающихся стран;

55. признает важность адекватных и предсказуемых финансовых ресурсов, в том числе для основанных на результатах выплат, в соответствующих случаях, для применения политических подходов и позитивных стимулов в целях сокращения выбросов в результате обезлесения и деградации лесов и повышения роли сохранения лесов, устойчивого управления лесами и увеличения накоплений уг- 
лерода в лесах; а также альтернативных стратегических подходов, таких как совместные подходы, связанные с предупреждением и адаптацией в интересах комплексного и устойчивого управления лесами; при одновременном подтверждении важности не связанных с углеродом выгод от таких подходов; поощрении координации поддержки, в частности со стороны государственных и частных, двусторонних и многосторонних источников, таких как Зеленый климатический фонд и альтернативные источники, согласно соответствующим решениям Конференции Сторон;

56. постановляет начать на своей двадцать второй сессии процесс определения информации для представления Сторонами в соответствии с пунктом 5 статьи 9 Соглашения с целью вынесения рекомендации для рассмотрения и принятия Конференцией Сторон, действующей в качестве совещания Сторон Парижского соглашения, на ее первой сессии;

57. также постановляет обеспечить, чтобы предоставление информации в соответствии с пунктом 7 статьи 9 Соглашения осуществлялось согласно условиям, процедурам и руководящим положениям, изложенным в пункте 96 ниже;

58. просит Вспомогательный орган для консультирования по научным и техническим аспектам разработать механизм учета финансовых ресурсов, предоставленных и мобилизованных при помощи государственного вмешательства, в соответствии с пунктом 7 статьи 9 Соглашения, для его рассмотрения Конференцией Сторон на ее двадцать четвертой сессии (ноябрь 2018 года) с целью вынесения рекомендации для рассмотрения и принятия Конференцией Сторон, действующей в качестве совещания Сторон Парижского соглашения, на ее первой сессии;

59. постановляет, что Зеленый климатический фонд и Глобальный экологический фонд, органы, которым будет поручено управление Финансовым механизмом Конвенции, а также Фонд для наименее развитых стран и Специальный фонд для борьбы с изменением климата, действующие под управлением Глобального экологического фонда, будут обслуживать Соглашение;

60. признает, что Адаптационный фонд может обслуживать Соглашение при условии принятия соответствующих решений Конференцией Сторон, действующей в качестве совещания Сторон Киотского протокола, и Конференцией Сторон, действующей в качестве совещания Сторон Парижского соглашения;

61. предлагает Конференции Сторон, действующей в качестве совещания Сторон Киотского протокола, рассмотреть вопрос, упомянутый в пункте 60 выше, и вынести рекомендацию Конференции Сторон, действующей в качестве совещания Сторон Парижского соглашения, на ее первой сессии;

62. рекомендует Конференции Сторон, действующей в качестве совещания Сторон Парижского соглашения, представить органам, которым будет поручено управление Финансовым механизмом Конвенции, руководящие указания в отношении политики, программных приоритетов и критериев приемлемости, связанных с Соглашением, для передачи Конференции Сторон;

63. постановляет, что руководящие указания органам, которым будет поручено управление Финансовым механизмом Конвенции в соответствующих решениях Конференции Сторон, включая органы, согласованные до принятия настоящего Соглашения, будут действовать mutatis mutandis;

64. также постановляет, что Постоянный комитет по финансам будет обслуживать Соглашение в соответствии с его функциями и задачами, установленными в рамках Конференции Сторон; 
65. настоятельно призывает учреждения, обслуживающие Соглашение, укрепить координацию и активизировать предоставление ресурсов в поддержку стратегий, осуществляемых по инициативе стран, с помощью упрощенных и эффективных процессов подачи заявок и процедур одобрения, а также за счет продолжения предоставления поддержки в обеспечении готовности Сторонам, являющимся развивающимися странами, в том числе наименее развитым странам и малым островным развивающимся государствам, когда это необходимо;

\section{Разработка и передача технологии}

66. принимает к сведению промежуточный доклад Исполнительного комитета по технологиям, посвященный руководству по более активному применению результатов оценок технологических потребностей, упоминаемый в документе FCCC/SB/2015/INF.3;

67. постановляет укрепить Механизм по технологиям и просит Исполнительный комитет по технологиям и Центр и Сеть по технологиям, связанным с изменением климата, в процессе поддержки осуществления Соглашения провести дальнейшую работу, касающуюся, в частности:
a) технологических исследований, разработок и демонстраций;
b) развития и укрепления внутренних возможностей и технологий;

68. просит Вспомогательный орган для консультирования по научным и техническим аспектам на его сорок четвертой сессии (май 2016 года) начать разработку рамочной основы по технологии, создаваемой согласно пункту 4 статьи 10 Соглашения, и доложить о своих выводах Конференции Сторон, с тем чтобы Конференция Сторон вынесла рекомендацию относительно рамочной основы для Конференции Сторон, действующей в качестве совещания Сторон Парижского соглашения, для ее рассмотрения и принятия на ее первой сессии, принимая во внимание, что эта рамочная основа должна содействовать, в частности:

a) проведению и обновлению оценок потребностей в технологии, а также более активной реализации их результатов, в частности планов действий и проектных идей по технологиям, посредством подготовки приемлемых для банков проектов;

b) оказанию более значительной финансовой и технической поддержки реализации результатов оценок технологических потребностей;

с) оценкам технологий, которые уже готовы для передачи;

d) улучшению благоприятных условий для развития и передачи социально и экологически оптимальных технологий и для устранения препятствий на пути их разработки и передачи;

69. постановляет, что Исполнительный комитет по технологиям и Центр и Сеть по технологиям, связанным с изменением климата, представляют Конференции Сторон, действующей в качестве совещания Сторон Парижского соглашения, через вспомогательные органы доклады о своей деятельности по поддержке осуществления Соглашения;

70. также постановляет проводить периодическую оценку эффективности и адекватности поддержки, оказываемой Механизму по технологиям, в поддержку осуществления Соглашения по вопросам, касающимся разработки и передачи технологий;

71. просит Исполнительный орган по осуществлению начать на своей сорок четвертой сессии разработку сферы охвата и условий проведения периодической 
оценки, упомянутой в пункте 70 выше, принимая во внимание обзор Центра и Сети по технологиям, связанным с изменением климата, упомянутый в пункте 20 приложения VII к решению 2/CР.17, и условий для подведения глобального итога, упомянутых в статье 14 Соглашения, для рассмотрения и принятия Конференцией Сторон на ее двадцать пятой сессии (ноябрь 2019 года);

\section{Укрепление потенцииала}

72. постановляет учредить Парижский комитет по укреплению потенциала, целью которого будет устранение пробелов и удовлетворение потребностей, как текущих, так и возникающих, в области осуществления деятельности по укреплению потенциала в Сторонах, являющихся развивающимися странами, и дальнейшего наращивания усилий по укреплению потенциала, в том числе с точки зрения обеспечения согласованности и координации деятельности по укреплению потенциала согласно Конвенции;

73. также постановляет, что Парижский комитет по укреплению потенциала будет руководить и осуществлять надзор за выполнением плана, упомянутого в пункте 74 ниже;

74. далее постановляет принять план работы на период 2016-2020 годов, предусматривающий следующие виды деятельности:

a) оценку того, как увеличить синергию на основе сотрудничества и избежать дублирования между существующими органами, учрежденными согласно Конвенции, которые осуществляют деятельность по укреплению потенциала, в том числе на основе сотрудничества с учреждениями в рамках и вне Конвенции;

b) выявление пробелов и потребностей в потенциале и предоставление рекомендаций в отношении путей восполнения этих пробелов и удовлетворения этих потребностей;

с) поощрение разработки и распространения инструментов и методологий для осуществления деятельности по укреплению потенциала;

d) развитие глобального, регионального, национального и субнационального сотрудничества;

е) выявление и сбор примеров эффективной практики, вызовов, опыта и извлеченных уроков в работе органов, учрежденных согласно Конвенции, в области укрепления потенциала;

f) изучение путей повышения сопричастности Сторон, являющихся развивающимися странами, делу укрепления и сохранения потенциала во времени и в пространстве;

g) выявление возможностей для укрепления потенциала на национальном, региональном и субрегиональном уровне;

h) развитие диалога, координации, сотрудничества и согласованности между соответствующими процессами и инициативами согласно Конвенции, в том числе путем обмена опытом о деятельности и стратегиях органов, учрежденных согласно Конвенции, в области укрепления потенциала;

i) предоставление секретариату руководящих указаний о ведении и дальнейшем развитии основанного на Интернете портала по укреплению потенциала;

75. постановляет, что Парижский комитет по укреплению потенциала будет ежегодно уделять основное внимание одной области или теме, касающейся расширения технических обменов по вопросам укрепления потенциала в целях по- 
лучения обновленных знаний об успехах и вызовах в деле эффективного укрепления потенциала в той или иной конкретной области;

76. просит Вспомогательный орган по осуществлению организовывать ежегодное сессионное совещание Парижского комитета по укреплению потенциала;

77. также просит Вспомогательный орган по осуществлению разработать круг ведения Парижского комитета по укреплению потенциала в контексте третьего всеобъемлющего обзора осуществления рамок по укреплению потенциала, также принимая во внимание пункты 75, 76, 77 и 78 выше и пункты 82 и 83 ниже, с тем чтобы рекомендовать проект решения по данному вопросу для рассмотрения и принятия Конференцией Сторон на ее двадцать второй сессии;

78. предлагает Сторонам представить свои мнения в отношении членского состава Парижского комитета по укреплению потенциала до 9 марта 2016 года ${ }^{2}$;

79. просит секретариат свести материалы, упомянутые в пункте 78 выше, в документ категории misc для рассмотрения Вспомогательным органом по осуществлению на его сорок четвертой сессии;

80. постановляет, что вклады в работу Парижского комитета по укреплению потенциала будут включать, помимо прочего, представления, результаты третьего всеобъемлющего обзора осуществления рамок для укрепления потенциала, ежегодный обобщающий доклад секретариата об осуществлении рамок для укрепления потенциала в развивающихся странах, подготавливаемый секретариатом доклад о компиляции и обобщении информации о работе по укреплению потенциала органов, учрежденных согласно Конвенции и Киотскому протоколу, и доклады о работе Дурбанского форума и доклады, размещенные на портале по укреплению потенциала;

81. просит Парижский комитет по укреплению потенциала подготавливать ежегодные технические доклады о прогрессе в его работе Вспомогательному органу по осуществлению и предоставлять их участникам сессий Вспомогательного органа по осуществлению, которые проводятся в связи с сессиями Конференции Сторон;

82. также просит Конференцию Сторон на ее двадцать пятой сессии (ноябрь 2019 года) рассмотреть прогресс, необходимость в расширении, эффективность и вопросы укрепления Парижского комитета по укреплению потенциала и предпринять любые действия, которые она сочтет целесообразными, с целью вынесения рекомендаций Конференции Сторон, действующей в качестве совещания Сторон Парижского соглашения, на ее первой сессии относительно укрепления институциональных механизмов укрепления потенциала в соответствии с пунктом 5 статьи 11 Соглашения;

83. призывает все Стороны обеспечить, чтобы вопросы образования, подготовки и информирования общественности, отраженные в статье 6 Конвенции и статье 12 Соглашения, надлежащим образом затрагивались в их вкладе в укрепление потенциала;

84. предлагает Конференции Сторон, действующей в качестве совещания Сторон Парижского соглашения, на ее первой сессии изучить пути активизации осуществления мер по обучению, информированию общественности, обеспечению участия общественности и доступа общественности к информации, с тем чтобы активизировать действия в рамках этого Соглашения;

\footnotetext{
${ }^{2}$ Стороны должны представить свои мнения через портал для представлений $<$ http://www.unfccc.int/5900>.
} 
Транспарентность действий и поддержки

85. постановляет учредить Инициативу в области укрепления потенциала в интересах транспарентности в целях наращивания организационного и технического потенциала в период до и после 2020 года. Эта инициатива будет оказывать поддержку развивающимся странам по их просьбе в своевременном удовлетворении требований к большей транспарентности, определенных в статье 13 Соглашения;

86. также постановляет, что Инициатива в области укрепления потенциала в интересах транспарентности будет направлена на:

a) укрепление национальных институтов для осуществления связанной с транспарентностью деятельности в соответствии с национальными приоритетами;

b) обеспечение соответствующих инструментов, подготовки кадров и оказание содействия в выполнении положений, изложенных в статье 13 Соглашения;

с) оказание содействия в повышении транспарентности с течением времени;

87. настоятельно призывает и просит Глобальный экологический фонд принять меры по оказанию поддержки в части учреждения и функционирования Инициативы в области укрепления потенциала в интересах транспарентности в качестве приоритетной потребности, связанной с представлением информации, в том числе за счет добровольных взносов в поддержку развивающихся стран в рамках шестого цикла пополнения ресурсов Глобального экологического фонда и будущих циклов пополнения для дополнения существующей поддержки стран в рамках Глобального экологического фонда;

88. постановляет оценить осуществление Инициативы в области укрепления потенциала в интересах транспарентности в контексте седьмого обзора финансового механизма;

89. просит Глобальный экологический фонд в качестве оперативного органа финансового механизма отражать в своих ежегодных докладах Конференции Сторон прогресс в разработке, развитии и осуществлении Инициативы в области укрепления потенциала в интересах транспарентности, о которой говорится в пункте 85 выше, начиная с 2016 года;

90. постановляет, что в соответствии с пунктом 2 статьи 13 Соглашения развивающимся странам будет обеспечена гибкость в осуществлении положений этой статьи, включая сферу охвата, частотность и степень детализации отчетности и сферу охвата обзора, и что данная сфера охвата обзора может предусматривать, что страновые обзоры являются факультативными, при этом такие гибкие аспекты найдут свое отражение в процессе разработки условий, процедур и руководящих принципов, упомянутых в пункте 92 ниже;

91. далее постановляет, что все Стороны, за исключением Сторон, являющихся наименее развитыми странами, и малых островных развивающихся государств, будут представлять информацию, упомянутую в пунктах 7, 8, 9 и 10 статьи 13, по мере необходимости не реже чем на двухгодичной основе и что Стороны, являющиеся наименее развитыми странами, и малые островные развивающиеся государства могут представлять такую информацию по своему усмотрению;

92. просит Специальную рабочую группу по Парижскому соглашению разработать рекомендации для условий, процедур и руководящих принципов в соот- 
ветствии с пунктом 13 статьи 13 Соглашения и установить год их первого и последующих пересмотров и обновлений, по мере необходимости, с регулярными интервалами для рассмотрения Конференцией Сторон на ее двадцать четвертой сессии с целью направления их Конференции Сторон, действующей в качестве совещания Сторон Парижского соглашения, для принятия на ее первой сессии;

93. также просит Специальную рабочую группу по Парижскому соглашению при разработке рекомендаций относительно условий процедуры руководящих принципов, упомянутых в пункте 92 выше, принять во внимание, в частности:

a) важность содействия улучшению с течением времени представления данных и транспарентности;

b) необходимость обеспечить гибкость для тех Сторон, являющихся развивающимися странами, которые с учетом их потенциала нуждаются в ней;

c) необходимость содействия транспарентности, точности, полноте, согласованности и сопоставимости;

d) необходимость избегать дублирования, а также возложения чрезмерного бремени на Стороны и на секретариат;

е) необходимость обеспечить, чтобы Стороны соблюдали по крайней мере частоту и качество отчетности согласно их соответствующим обязательствам по Конвенции;

f) необходимость обеспечить избежание двойного подсчета;

g) необходимость обеспечить целостность окружающей среды;

94. также просит Специальную рабочую группу по Парижскому соглашению при разработке условий, процедур и руководящих принципов, упомянутых в пункте 92 выше, опираться на опыт других текущих соответствующих процессов согласно Конвенции и принимать их во внимание;

95. просит Специальную рабочую группу по Парижскому соглашению при разработке условий, процедур и руководящих принципов, упомянутых в пункте 92 выше, принимать во внимание, в частности:

a) типы гибкости, доступные тем развивающимся странам, которые нуждаются в ней с учетом их потенциала;

b) согласованность между методологией, сообщаемой в определяемых на национальном уровне вкладах, и методологией представления информации о прогрессе в деле достижения соответствующих вкладов отдельных Сторон;

c) что Стороны сообщают информацию о мерах по адаптации и планировании, включая, в соответствующих случаях, свои национальные планы в области адаптации, с тем чтобы проводить коллективный обмен информацией и делиться извлеченными уроками;

d) предоставленную поддержку, активизацию оказания поддержки как в целях адаптации, так и предотвращения изменения климата, при помощи, помимо прочего, общих табличных форм для предоставления информации о поддержке и с учетом вопросов, рассмотренных Вспомогательным органом для консультирования по научным и техническим аспектам в контексте методологий для представления информации о финансах, и активизацию представления информации развивающимися странами о полученной поддержке, в том числе об ее использовании, воздействии и предполагаемых результатах; 
е) информацию, содержащуюся в двухгодичных оценках и других докладах Постоянного комитета по финансам и других соответствующих органов в рамках Конвенции;

f) информацию о социально-экономических последствиях мер реагирования;

96. также просит Специальную рабочую группу по Парижскому соглашению при разработке рекомендаций в отношении условий, процедур и руководящих принципов, упомянутых в пункте 92 выше, повысить транспарентность поддержки, оказываемой в соответствии со статьей 9 Соглашения;

97. далее просит Специальную рабочую группу по Парижскому соглашению сообщать о прогрессе в работе над условиями, процедурами и руководящими принципами, упоминаемыми в пункте 92 выше, на будущих сессиях Конференции Сторон, и завершить эту работу не позднее 2018 года;

98. постановляет, что условия, процедуры и руководящие принципы, разработанные согласно пункту 92 выше, применяются после вступления Парижского соглашения в силу;

99. также постановляет, что условия, процедуры и руководящие принципы этих рамок для обеспечения транспарентности должны опирать на систему измерений, представления отчетности и проверки, созданную в соответствии с пунктами 40-47 и 60-64 решения 1/СР.16 и пунктами 12-62 решения 2/СР.17, и призваны заменить ее в конечном итоге непосредственно после представления двухгодичных докладов и докладов с обновленной информацией для двухгодичных докладов;

\section{Глобальное подведение итогов}

100. nросит Специальную рабочую группу по Парижскому соглашению выявить источники вкладов для глобального мероприятия по подведению итогов, упомянутого в статье 14 Соглашения, и представить информацию Конференции Сторон, с тем чтобы Конференция Сторон вынесла рекомендацию для Конференции Сторон, действующей в качестве совещания Сторон Парижского соглашения, для рассмотрения и принятия на ее первой сессии, включая, среди прочего:
а) информацию о:
i) совокупном эффекте определяемых на национальном уровне вкладов, сообщенных Сторонами;

ii) статусе усилий по адаптации, поддержке, опыте и приоритетах из сообщений, упомянутых в пунктах 10 и 11 статьи 7 Соглашения, и докладов, упомянутых в пункте 7 статьи 13 Соглашения;

iii) мобилизации и предоставлении поддержки;

b) последние доклады Межправительственной группы экспертов по изменению климата;

с) доклады вспомогательных органов;

101. также просит Вспомогательный орган для консультирования по научным и техническим аспектам оказать консультационную помощь по вопросу о том, каким образом оценки Межправительственной группы экспертов по изменению климата могут служить информационным вкладом в глобальное подведение итогов осуществления Соглашения во исполнение его статьи 14 , и представить доклад по этому вопросу Специальной рабочей группе по Парижскому соглашению на ее второй сессии; 
102. далее просит Специальную рабочую группу по Парижскому соглашению разработать условия для глобального подведения итогов, упомянутого в статье 14 Соглашения, и представить доклад Конференции Сторон с целью вынесения рекомендации Конференции Сторон, действующей в качестве совещания Сторон Парижского соглашения, для рассмотрения и принятия на ее первой сессии;

\section{Содействие осущчествлению и соблюдению}

103. постановляет, что комитет, упомянутый в пункте 2 статьи 15 Соглашения, будет состоять из 12 членов, обладающих признанной компетенцией в соответствующих научных, технических, социально-экономических или юридических областях, которые будут избраны Конференцией Сторон, действующей в качестве совещания Сторон Парижского соглашения, на основе принципа справедливого географического распределения, по два члена от каждой из пяти региональных групп Организации Объединенных Наций и одному члену от каждого малого островного развивающегося государства и наименее развитой страны, учитывая при этом цель обеспечения гендерного баланса;

104. просит Специальную рабочую группу по Парижскому соглашению разработать условия и процедуры для эффективного функционирования комитета, упомянутого в пункте 2 статьи 15 Соглашения, с тем чтобы Специальная рабочая группа по Парижскому соглашению могла завершить свою работу над этими условиями и процедурами для рассмотрения и принятия Конференцией Сторон, действующей в качестве совещания Сторон Парижского соглашения, на ее первой сессии;

\section{Заключительные положения}

105. также просит секретариат исключительно для целей статьи 21 Соглашения разместить на своем веб-сайте в дату принятия Соглашения, а также в докладе Конференции Сторон на ее двадцать первой сессии самую свежую информацию об общих объемах и процентной доле выбросов парниковых газов, сообщенную Сторонами Конвенции в своих национальных сообщениях, докладах о кадастрах парниковых газов, двухгодичных докладах или докладах с обновленной информацией для двухгодичных докладов;

\section{IV. Активизация действий в период до 2020 года}

106. постановляет обеспечить самый высокий возможный уровень усилий по предотвращению изменения климата в период до 2020 года, в том числе:

a) настоятельно призывая все Стороны Киотского протокола, которые еще не сделали этого, ратифицировать и осуществлять Дохинскую поправку к Киотскому протоколу;

b) настоятельно призывая все Стороны, которые еще не сделали этого, принять и выполнять обязательства по предотвращению изменения климата согласно Канкунским договоренностям;

с) вновь подтверждая свою решимость, как изложено в пунктах 3 и 4 решения 1/СР.19, ускорить полное осуществление решений, составляющих согласованный итоговый документ согласно решению 1/СР.13, и повысить уровень амбициозности целей в период до 2020 года, с тем чтобы обеспечить самые высокие возможные усилия по предотвращению изменения климата всех Сторон в соответствии с Конвенцией; 
d) предлагая Сторонам, являющимся развивающимися странами, которые не представили свои первые двухгодичные доклады, содержащие обновленную информацию, сделать это как можно скорее;

е) настоятельно призывая все Стороны принять своевременное участие в существующих процессах измерения, отчетности и проверки согласно Канкунским договоренностям, с тем чтобы продемонстрировать прогресс, достигнутый в осуществлении своих обещаний по предотвращению изменения климата;

107. призывает Стороны способствовать добровольному аннулированию заинтересованными кругами, являющимися Сторонами и не являющимися Сторонами, единиц, введенных в обращение согласно Киотскому протоколу, без их двойного подсчета, в том числе сертифицированных сокращений выбросов, которые действительны в течение второго периода действия обязательств;

108. настоятельно призывает принимающие и приобретающие Стороны транспарентным образом сообщать о переданных на международном уровне результатах предотвращения изменения климата, в том числе результатах, используемых для выполнения международных обязательств, и единицах сокращения выбросов, выпущенных в рамках Киотского протокола, с целью недопущения ущерба для окружающей среды и избежания двойного подсчета;

109. признает социальную, экономическую и экологическую ценность добровольных действий по предотвращению изменения климата и их сопутствующие выгоды для адаптации, здоровья и устойчивого развития;

110. постановляет в период 2016-2020 годов укрепить существующий процесс технического изучения, определенный в пункте 5 а) решения 1/СР.19 и пункте 19 решения 1/CР.20, принимая во внимание последние научные знание, в том числе:

a) призывая Стороны, органы Конвенции и международные организации к участию в этом процессе, в том числе, когда это необходимо, в сотрудничестве с соответствующими заинтересованными кругами, не являющимися Сторонами, с тем чтобы делиться своим опытом и предложениями, в том числе по итогам региональных мероприятий, и сотрудничеству в деле содействия осуществлению политики, практики и мер, определенных в рамках этого процесса, в соответствии с национальными приоритетами в области устойчивого развития;

b) стремясь расширить, в консультации со Сторонами, доступ и участие в этом процессе экспертов из Сторон, являющихся развивающимися странами, и из других стран;

c) обращаясь к Исполнительному комитету по технологиям и Центру и Сети по технологиям, связанным с изменением климата, с просьбой в соответствии с их соответствующими мандатами:

i) принимать участие в совещаниях технических экспертов и активизировать свои усилия по оказанию поддержки и содействия Сторонам в более широком осуществлении политики, практики и мер, определенных в ходе этого процесса;

ii) предоставлять регулярно обновленную информацию в ходе совещаний технических экспертов, посвященных прогрессу, достигнутому в деле содействия осуществлению политики, практики и действий, определенных ранее в ходе этого процесса;

iii) включать информацию о своей деятельности в рамках этого процесса в их совместный ежегодный доклад Конференции Сторон; 
d) поощряя Стороны к эффективному использованию Центра и Сети по технологиям, связанным с изменением климата, с целью получения помощи в деле разработки экономически, экологически и социально жизнеспособных предложений по проектам в наиболее перспективных с точки зрения предотвращения изменения климата областях, выявленных в ходе этого процесса;

111. призывает оперативные органы финансового механизма Конвенции участвовать в совещаниях технических экспертов и информировать участников об их вкладе в содействие прогрессу в осуществлении политики, практики и мер, определенных в процессе технического изучения;

112. просит секретариат организовать процесс, упомянутый в пункте 110 выше, и распространять его результаты, в том числе:

a) путем организации, в консультации с Исполнительным комитетом по технологиям и соответствующими экспертными организациями, регулярных совещаний технических экспертов, посвященных конкретным видам политики, практики и действий, представляющих передовую практику, которые могут быть масштабируемыми и воспроизводимыми;

b) обновления на ежегодной основе, после совещаний, упомянутых в пункте 112 а) выше, и в сроки, позволяющие использовать их в качестве вклада в резюме для директивных органов, упомянутых в пункте 112 с) ниже, технического документа о выгодах предотвращения изменения климата и сопутствующих выгодах от политики, практики и действий для повышения уровня амбициозности целей в области предотвращения изменения климата, а также о вариантах поддержки их осуществления, информация о которых должна быть доступна в удобном для пользователя формате в режиме онлайн;

c) подготовки в консультации с лидерами, упомянутыми в пункте 122 ниже, резюме для директивных органов с информацией о конкретных видах политики, практики и действий, представляющих передовую практику, которые могут быть масштабируемыми и воспроизводимыми, и о вариантах поддержки их осуществления, а также о соответствующих совместных инициативах и публикации этих резюме не позднее чем за два месяца до начала каждой сессии Конференции Сторон в качестве вклада в мероприятие высокого уровня, упомянутого в пункте 121 ниже;

113. постановляет, что процесс, упомянутый в пункте 110 выше, должен быть организован совместно Вспомогательным органом по осуществлению и Вспомогательным органом для консультирования по научным и техническим аспектам и должен осуществляться на постоянной основе до 2020 года;

114. также постановляет провести в 2017 году оценку процесса, упомянутого в пункте 110 выше, с тем чтобы повысить его эффективность;

115. постановляет активизировать предоставление срочной и адекватной финансовой, технологической поддержки и поддержки в области укрепления потенциала Сторонами, являющимися развитыми странами, с тем чтобы повысить уровень амбициозности целей действий Сторон в период до 2020 года, и в этой связи настоятельно призывает Стороны, являющиеся развитыми странами, увеличить уровень своей финансовой поддержки на основе конкретной «дорожной карты», предусматривающей достижение к 2020 году цели совместно выделять 100 млрд. долл. в год на предотвращение изменения климата и адаптацию, а также значительно увеличить финансирование деятельности по адаптации по сравнению с текущими уровнями и обеспечить в дальнейшем соответствующую передачу технологий и поддержку в наращивании потенциала; 
116. постановляет провести стимулирующий диалог в связи с двадцать второй сессией Конференции Сторон для оценки хода осуществления пунктов 3 и 4 решения 1/CР.19 и выявить соответствующие возможности для активизации предоставления финансовых ресурсов, в том числе для разработки и передачи технологии и содействия укреплению потенциала, в целях выявления путей повышения амбициозности усилий всех Сторон по предотвращению изменения климата, включая выявление соответствующих возможностей для активизации предоставления и мобилизации поддержки и обеспечения благоприятных условий;

117. признает с удовлетворением результаты Лимско-Парижской повестки дня для действий, которые опираются на итоги Встречи на высшем уровне по вопросам климата, созванной 23 сентября 2014 года Генеральным секретарем Организации Объединенных Наций;

118. приветствует усилия заинтересованных кругов, не являющихся Сторонами, по наращиванию масштабов их действий по борьбе с изменением климата и поощряет регистрацию этих действий на платформе Зоны климатических действий негосударственных субъектов ${ }^{3}$;

119. призывает Стороны тесно сотрудничать с заинтересованными кругами, не являющимися Сторонами, в целях активизации усилий по укреплению действий по предотвращению изменения климата и адаптации;

120. также призывает заинтересованные круги, не являющиеся Сторонами, расширить свое участие в процессах, упомянутых в пунктах 110 выше и 125 ниже;

121. постановляет созывать во исполнение решения $1 /$ СР.20, пункт 21 , опираясь на Лимско-Парижскую повестку дня для действий, в связи с каждой сессией Конференции Сторон в течение периода 2016-2020 годов мероприятие высокого уровня, которое будет:

a) содействовать дальнейшему укреплению участия на высоком уровне в осуществлении политических вариантов и действий, связанных с процессами, упомянутыми в пунктах 110 выше и 125 ниже, основываясь на резюме для директивных органов, упомянутое в пункте 112 с) выше;

b) служить возможностью для объявления новых или более активных добровольных усилий, инициатив и коалиций, включая осуществление политики, практики и действий, являющихся результатом процессов, упомянутых в пунктах 110 выше и 125 ниже и изложенных в резюме для директивных органов, упомянутом в пункте 112 с) выше;

c) подводить итоги соответствующих процессов и признавать новые или более активные добровольные усилия, инициативы и коалиции;

d) обеспечивать конструктивные и регулярные возможности для эффективного участия деятелей высокого уровня от Сторон, международных организаций, международных совместных инициатив и заинтересованных кругов, не являющихся Сторонами;

122. постановляет назначить двух лидеров высокого уровня, действующих от имени Председателя Конференции Сторон, для оказания содействия путем более активного взаимодействия на высоком уровне в период 2016-2020 годов эффективному осуществлению текущих усилий, а также укреплению и принятию новых или более активных добровольных усилий, инициатив и коалиций, в том числе путем:

\footnotetext{
${ }^{3}<$ http://climateaction.unfccc.int $>$.
} 
a) проведения работы с Исполнительным секретарем и нынешним и будущими Председателями Конференции Сторон в целях координации ежегодного мероприятия высокого уровня, упомянутого в пункте 121 выше;

b) сотрудничества с заинтересованными Сторонами и заинтересованными кругами, не являющимися Сторонами, включая продвижение добровольных инициатив в рамках Лимско-Парижской повестки дня для действий;

c) предоставления секретариату руководящих указаний в отношении организации совещаний технических экспертов, упомянутых в пункте 112 а) выше и пункте 130 а) ниже;

123. также постановляет, что лидеры высокого уровня, упомянутые в пункте 122 выше, обычно должны выполнять свои функции в течение двух лет, при этом их срок полномочий пересекается на один полный год для обеспечения преемственности следующим образом:

a) Председатель Конференции Сторон на ее двадцать первой сессии должен назначить одного лидера, который будет выполнять свои функции в течение одного года с даты назначения до последнего дня работы двадцать второй сессии Конференции Сторон;

b) Председатель Конференции Сторон на ее двадцать второй сессии должен назначить одного лидера, который будет выполнять свои функции в течение двух лет с даты назначения до последнего дня работы двадцать третьей сессии Конференции Сторон (ноябрь 2017 года);

c) после этого каждый последующий Председатель Конференции Сторон должен назначать одного лидера, который должен выполнять свои функции в течение двух лет и замещать ранее назначенного лидера, срок полномочий которого истек;

124. призывает все заинтересованные Стороны и соответствующие организации оказывать поддержку работе лидеров, упомянутых в пункте 122 выше;

125. постановляет начать в период 2016-2020 годов процесс технического изучения действий по адаптации;

126. также постановляет, что процесс технического изучения действий по адаптации, упомянутый в пункте 125 выше, будет направлен на выявление конкретных возможностей для повышения резильентности, снижения уязвимости, а также на углубление понимания и активизацию осуществления действий по адаптации;

127. далее постановляет, что упомянутый в пункте 125 выше процесс технического изучения должен быть организован совместно Вспомогательным органом по осуществлению и Вспомогательным органом для консультирования по научным и техническим аспектам и осуществляться Комитетом по адаптации;

128. постановляет, что процесс, упомянутый в пункте 125 выше, будет осуществляться путем:

a) налаживания обмена эффективной практикой, опытом и извлеченными уроками;

b) выявления действий, которые способны значительно активизировать осуществление действий по адаптации, в том числе действий, которые могли бы способствовать экономической диверсификации и имеют параллельные преимущества для предотвращения изменения климата;

с) поощрения совместных действий по адаптации; 
d) выявления вариантов укрепления благоприятных условий и активизации предоставления поддержки в целях адаптации в контексте конкретных политики, стратегий и действий;

129. также постановляет, что процесс технического изучения действий по адаптации, упомянутый в пункте 125 выше, будет учитывать процессы, условия, материалы и результаты и уроки, извлеченные в ходе процесса технического изучения действий по предотвращению изменения климата, упомянутого в пункте 110 выше;

130. просит секретариат оказывать поддержку процессу технического изучения, упомянутому в пункте 125 выше, путем:

a) организации регулярных совещаний технических экспертов, уделяющих основное внимание конкретным политике, стратегиям и действиям;

b) ежегодной подготовки технического доклада о возможностях активизации действий по адаптации, а также вариантах оказания поддержки в их реализации на основе итогов упомянутых в пункте 130 а) выше совещаний и своевременно для того, чтобы служить информационным вкладом в резюме для директивных органов, упомянутое в пункте 112 с) выше, информация о котором должна предоставляться в онлайновом режиме в удобном для пользователей формате;

131. постановляет, что при осуществлении процесса, упомянутого в пункте 125 выше, Комитет по адаптации будет взаимодействовать с существующими механизмами связанных с адаптацией программ работы, органов и учреждений согласно Конвенции и изучать возможности их учета, налаживания синергизма и их использования в целях обеспечения слаженности и максимальной отдачи;

132. также постановляет осуществлять в сочетании с оценкой, упомянутой в пункте 120 выше, оценку процесса, упомянутого в пункте 125 выше, с тем чтобы повысить ее эффективность;

133. призывает Стороны и организации-наблюдатели представить до 3 февраля 2016 года информацию о возможностях, упомянутых в пункте 126 выше;

\section{V. Заинтересованные круги, не являющиеся Сторонами}

134. приветствует усилия всех заинтересованных кругов, не являющихся Сторонами, по решению проблем, связанных с изменением климата, и реагированию на них, в том числе усилия гражданского общества, частного сектора, финансовых институтов, городов и других субнациональных органов власти;

135. призывает заинтересованные круги, не являющиеся Сторонами, которые упомянуты в пункте 134 выше, наращивать масштабы их усилий и поддержки действиям по сокращению выбросов и/или повышению сопротивляемости и снижению уязвимости к неблагоприятным последствиям изменения климата и демонстрировать эти усилия на платформе Зоны климатических действий негосударственных субъектов ${ }^{4}$, упомянутой в пункте 118 выше;

136. признает необходимость в расширении знаний, технологий, практики и усилий местных общин и коренных народов по реагированию на изменение климата и принятию ответных мер и учреждает платформу для обмена опытом и совместного использования передовой практики в деле предотвращения изменения климата и адаптации к нему на целостной и комплексной основе;

\footnotetext{
${ }^{4}<$ http://climateaction.unfecc.int $>$.
} 
137. также признает важную роль стимулирования деятельности по сокращению выбросов, включая использование таких инструментов, как соответствующая внутренняя политика и установление цен на углерод;

\section{VI. Административные и бюджетные вопросы}

138. принимает к сведению сметные бюджетные последствия деятельности, которую должен осуществить секретариат в соответствии с настоящим решением, и просит, чтобы действия секретариата, запрашиваемые в настоящем решении, осуществлялись при наличии финансовых ресурсов;

139. подчеркивает безотлагательный характер выделения дополнительных ресурсов для осуществления соответствующих действий, в том числе действий, упомянутых в настоящем решении, и для осуществления программы работы, упомянутой в пункте 9 выше;

140. настоятельно призывает Стороны вносить добровольные взносы для своевременного осуществления настоящего решения. 


\section{Приложение}

\section{Парижское соглашение}

Стороны настоящего Соглашения,

будучи Сторонами Рамочной конвенции Организации Объединенных Наций об изменении климата, далее упоминаемой «Конвенция»,

во исполнение мандата Дурбанской платформы для более активных действий, учрежденной решением 1/CP.17 Конференции Сторон Конвенции на ее семнадцатой сессии,

стремясь к цели Конвенции и в соответствии с ее принципами, в том числе с принципами равенства и общей, но дифференцированной ответственности и соответствующих возможностей, в свете различных национальных условий,

признавая необходимость в эффективном и прогрессивном реагировании на срочную угрозу изменения климата на основе наилучших имеющихся научных знаний,

также признавая конкретные потребности и особые обстоятельства Сторон, являющихся развивающимися странами, особенно тех, которые особо уязвимы к неблагоприятным последствиям изменения климата, как это предусмотрено в Конвенции,

полностью принимая во внимание конкретные потребности и особые условия наименее развитых стран в отношении финансирования и передачи технологий,

признавая, что Стороны могут страдать не только от изменения климата, но также от воздействий мер, принимаемых в целях реагирования на него,

подчеркивая неразрывную связь действий по борьбе с изменением климата, мер реагирования на изменение климата и воздействий изменения климата со справедливым доступом к устойчивому развитию и ликвидацией нищеты,

признавая основополагающий приоритет обеспечения продовольственной безопасности и ликвидации голода и особую уязвимость систем производства продовольствия к неблагоприятным последствиям изменения климата,

принимая во внимание настоятельную необходимость справедливых изменений в области рабочей силы и создания достойных условий труда и качественных рабочих мест в соответствии с определяемыми на национальном уровне приоритетами развития,

признавая, что изменение климата является общей озабоченностью человечества, Стороны должны, при осуществлении действий в целях решения проблем, связанных с изменением климата, уважать, поощрять и принимать во внимание свои соответствующие обязательства в области прав человека, право на здоровье, права коренных народов, местных общин, мигрантов, детей, инвалидов и лиц, находящихся в уязвимом положении, и право на развитие, а также гендерное равенство, расширение возможностей женщин и межпоколенческую справедливость,

признавая важность сохранения и увеличения, в зависимости от обстоятельств, поглотителей и накопителей парниковых газов, упомянутых в Конвенции, 
отмечая важность обеспечения целостности всех экосистем, включая океаны, и защиты биоразнообразия, признаваемых некоторыми культурами как МатьЗемля, и отмечая важность для некоторых концепции «климатическая справедливость», при осуществлении действий по решению проблем, связанных с изменением климата,

подтверждая важность просвещения, подготовки кадров, информирования общественности, участия общественности, доступа общественности к информации и сотрудничества на всех уровнях по вопросам, рассматриваемым в настоящем Соглашении,

признавая важность задействования всех уровней правительства и различных субъектов, согласно соответствующему национальному законодательству Сторон, в решении проблем, связанных с изменением климата,

также признавая, что устойчивые жизненные уклады и устойчивые структуры потребления и производства, при ведущей роли Сторон, являющихся развитыми странами, играют важную роль в решении проблем, связанных с изменением климата,

договорились о следующем:

\section{Статья 1}

Для целей настоящего Соглашения применяются все определения, содержащиеся в статье 1 Конвенции. В добавление к этому:

1. «Конвенция» означает Рамочную конвенцию Организации Объединенных Наций об изменении климата, принятую в Нью-Йорке 9 мая 1992 года.

2. «Конференция Сторон» означает Конференцию Сторон Конвенции.

3. «Сторона» означает Сторону настоящего Соглашения.

\section{Статья 2}

1. Настоящее Соглашение, активизируя осуществление Конвенции, включая ее цель, направлено на укрепление глобального реагирования на угрозу изменения климата в контексте устойчивого развития и усилий по искоренению нищеты, в том числе посредством:

a) удержания прироста глобальной средней температуры намного ниже $2{ }^{\circ} \mathrm{C}$ сверх доиндустриальных уровней и приложения усилий в целях ограничения роста температуры до $1,5{ }^{\circ} \mathrm{C}$, признавая, что это значительно сократит риски и воздействия изменения климата;

b) повышения способности адаптироваться к неблагоприятным воздействиям изменения климата и содействия сопротивляемости к изменению климата и развитию при низком уровне выбросов парниковых газов таким образом, который не ставит под угрозу производство продовольствия;

с) приведения финансовых потоков в соответствие с траекторией в направлении развития, характеризующегося низким уровнем выбросов и сопротивляемостью к изменению климата.

2. Настоящее Соглашение будет осуществляться таким образом, чтобы отразить справедливость и принцип общей, но дифференцированной ответственности и соответствующих возможностей в свете различных национальных условий. 


\section{Статья 3}

В качестве определяемых на национальном уровне вкладов в глобальное реагирование на изменение климата все Стороны должны предпринимать и сообщать амбициозные усилия, как это определено в статьях 4, 7, 9, 10, 11 и 13, в целях выполнения задачи настоящего Соглашения, как она изложена в статье 2 . Усилия всех Сторон представляют собой продвижение вперед с течением времени, при признании необходимости оказания поддержки Сторонам, являющимся развивающимися странами, в целях эффективного осуществления настоящего Соглашения.

\section{Статья 4}

1. Для достижения долгосрочной глобальной температурной цели, установленной в статье 2, Стороны стремятся как можно скорее достичь глобального пика выбросов парниковых газов, признавая, что достижение такого пика потребует более длительного времени у Сторон, являющихся развивающимися странами, а также добиться впоследствии быстрых сокращений в соответствии с наилучшими имеющимися научными знаниями, в целях достижения сбалансированности между антропогенными выбросами из источников и абсорбцией поглотителями парниковых газов во второй половине этого века на основе справедливости и в контексте устойчивого развития и усилий по искоренению нищеты.

2. Каждая Сторона подготавливает, сообщает и сохраняет последовательные определяемые на национальном уровне вклады, которых она намеревается достичь. Стороны принимают внутренние меры по предотвращению изменения климата для достижения целей таких вкладов.

3. Каждый последующий определяемый на национальном уровне вклад Стороны представляет собой продвижение вперед сверх текущего определяемого на национальном уровне вклада и отражает ее как можно более высокую амбициозность, отражая ее общую, но дифференцированную ответственность и соответствующие возможности, в свете различных национальных условий.

4. Стороны, являющиеся развитыми странами, продолжают выполнять ведущую роль путем установления целевых показателей абсолютного сокращения выбросов в масштабах всей экономики. Стороны, являющиеся развивающимися странами, должны продолжать активизировать свои усилия по предотвращению изменения климата, и к ним обращается призыв перейти со временем к целевым показателям ограничения или сокращения выбросов в масштабах всей экономики в свете различных национальных условий.

5. Сторонам, являющимся развивающимися странами, предоставляется поддержка для осуществления настоящей статьи в соответствии со статьями 9, 10 и 11 при признании того, что более значительная поддержка для Сторон, являющихся развивающимися странами, позволит повысить амбициозность их действий.

6. Наименее развитые страны и малые островные развивающиеся государства могут подготавливать и сообщать стратегии, планы и действия в целях развития при низком уровне выбросов парниковых газов, отражающих их особые условия.

7. Сопутствующие выгоды для предотвращения изменения климата в результате действий по адаптации и/или планов диверсификации экономики Сторон могут способствовать результатам в области предотвращения изменения климата согласно настоящей статье. 
8. При сообщении своих определяемых на национальном уровне вкладов все Стороны представляют информацию, необходимую для обеспечения ясности, транспарентности и понимания, в соответствии с решением 1/СР.21 и любыми соответствующими решениями Конференции Сторон, действующей в качестве совещания Сторон Парижского соглашения.

9. Каждая Сторона сообщает определяемый на национальном уровне вклад раз в пять лет в соответствии с решением 1/CР.21 и соответствующими решениями Конференции Сторон, действующей в качестве совещания Сторон Парижского соглашения, и использует в качестве информационной основы результаты глобального подведения итогов, упомянутого в статье 14.

10. Конференция Сторон, действующая в качестве совещания Сторон Парижского соглашения, рассматривает вопрос об общих сроках для определяемых на национальном уровне вкладов на своей первой сессии.

11. Сторона может в любое время скорректировать свой существующий определяемый на национальном уровне вклад в целях повышения его уровня амбициозности в соответствии с руководящими указаниями, принятыми Конференцией Сторон, действующей в качестве совещания Сторон Парижского соглашения.

12. Определяемые на национальном уровне вклады, сообщенные Сторонами, регистрируются в публичном реестре, который ведется секретариатом.

13. Стороны ведут учет своих определяемых на национальном уровне вкладов. При учете антропогенных выбросов и абсорбции, соответствующих их определяемым на национальном уровне вкладам, Стороны способствуют экологической целостности, транспарентности, точности, полноте, сопоставимости и согласованности, а также обеспечивают недопущение двойного учета в соответствии с руководящими указаниями, принятыми Конференцией Сторон, действующей в качестве совещания Сторон Парижского соглашения.

14. В контексте своих определяемых на национальном уровне вкладов при признании и осуществлении действий по предотвращению изменения климата в отношении антропогенных выбросов и абсорбции Стороны должны принимать во внимание надлежащим образом существующие методы и руководящие указания согласно Конвенции в свете положений пункта 13 настоящей статьи.

15. Стороны принимают во внимание при осуществлении настоящего Соглашения обеспокоенности Сторон, экономика которых наиболее пострадала от воздействий мер реагирования, особенно Сторон, являющихся развивающимися странами.

16. Стороны, в том числе региональные организации экономической интеграции и их государства-члены, которые достигли соглашения действовать совместно согласно пункту 2 настоящей статьи, уведомляют секретариат об условиях этого соглашения, в том числе об уровне выбросов, установленного для каждой Стороны на соответствующий период времени, когда они сообщают свой определяемый на национальном уровне вклад. Секретариат в свою очередь информирует Стороны и сигнатариев Конвенции об условиях этого соглашения.

17. Каждая Сторона такого соглашения несет ответственность за свой уровень выбросов, как он установлен в соглашении, упомянутом в пункте 16 выше, в соответствии с пунктами 13 и 14 настоящей статьи и статьями 13 и 15.

18. Если Стороны, действующие совместно, делают это в рамках региональной организации экономической интеграции, которая сама является Стороной настоящего Соглашения, или вместе с ней, каждое государство - член этой региональной организации экономической интеграции индивидуально и вместе с регио- 
нальной организацией экономической интеграции несет ответственность за свой уровень выбросов, как он установлен в соглашении, о котором было сообщено согласно пункту 16 настоящей статьи, в соответствии с пунктами 13 и 14 настоящей статьи и статьями 13 и 15.

19. Все Стороны должны стремиться формулировать и сообщать долгосрочные стратегии развития с низким уровнем выбросов парниковых газов с учетом статьи 2, принимая во внимание свою общую, но дифференцированную ответственность и соответствующие возможности, в свете различных национальных условий.

\section{Статья 5}

1. Стороны должны предпринимать действия по охране и повышению качества, в соответствующих случаях, поглотителей и накопителей парниковых газов, как это упомянуто в статье 4 , пункт 1 d), Конвенции, включая леса.

2. К Сторонам обращается призыв предпринимать действия по осуществлению и поддержке, в том числе при помощи основанных на результатах выплат, существующих рамок, как они изложены в соответствующих руководящих указаниях и решениях, уже принятых согласно Конвенции, для политических подходов и позитивных стимулов для деятельности, связанной с сокращением выбросов в результате обезлесения и деградации лесов и с ролью сохранения лесов, устойчивого управления лесами и увеличения накоплений углерода в лесах в развивающихся странах; и альтернативными политическими подходами, такими как подходы, сочетающие предотвращение изменения климата и адаптацию, в целях комплексного и устойчивого управления лесами, при подтверждении важности стимулирования надлежащим образом неуглеродных выгод, связанных с такими подходами.

\section{Статья 6}

1. Стороны признают, что некоторые Стороны используют добровольное сотрудничество при осуществлении своих определяемых на национальном уровне вкладов, с тем чтобы создать возможности для повышения амбициозности их действий по предотвращению изменения климата и адаптации и поощрения устойчивого развития и экологической целостности.

2. Стороны, когда они участвуют на добровольной основе в совместных подходах, которые включают использование передаваемых на международном уровне результатов предотвращения изменения климата для целей определяемых на национальном уровне вкладов, поощряют устойчивое развитие и обеспечивают экологическую целостность и транспарентность, в том числе в сфере управления, и применяют надежный учет для обеспечения, помимо прочего, недопущения двойного учета в соответствии с руководящими указаниями, принятыми Конференцией Сторон, действующей в качестве совещания Сторон Парижского соглашения.

3. Использование передаваемых на международном уровне результатов предотвращения изменения климата для достижения определяемых на национальном уровне вкладов согласно настоящему Соглашению осуществляется на добровольной основе и с разрешения участвующих Сторон.

4. Настоящим учреждается механизм для содействия сокращению выбросов парниковых газов и поддержки устойчивого развития, под руководством и управлением Конференции Сторон, действующей в качестве совещания Сторон Парижского соглашения, для использования Сторонами на добровольной основе. Он функ- 
ционирует под надзором органа, назначенного Конференцией Сторон, действующей в качестве совещания Сторон Парижского соглашения, и имеет целью:

a) содействие сокращению выбросов парниковых газов при поощрении устойчивого развития;

b) стимулирование и поощрение участия государственных и частных субъектов, уполномоченных Стороной, в сокращении выбросов парниковых газов;

c) содействие сокращению уровней выбросов в принимающей Стороне, которая будет получать выгоды от деятельности по предотвращению изменения климата, результатом которой являются сокращения выбросов, которые могут также использоваться другой Стороной для выполнения своего определяемого на национальном уровне вклада; и

d) обеспечение общего сокращения глобальных выбросов.

5. Сокращение выбросов, являющееся результатом применения механизма, упомянутого в пункте 4 настоящей статьи, не используется для демонстрации достижения принимающей Стороной определяемого на национальном уровне вклада, если оно используется другой Стороной для демонстрации достижения ее определяемого на национальном уровне вклада.

6. Конференция Сторон, действующая в качестве совещания Сторон Парижского соглашения, обеспечивает, чтобы часть поступлений от деятельности в рамках механизма, упомянутого в пункте 4 настоящей статьи, использовалась для покрытия административных расходов, а также для оказания помощи Сторонам, являющимся развивающимися странами, которые особенно уязвимы к неблагоприятным последствиям изменения климата, в покрытии расходов на адаптацию.

7. Конференция Сторон, действующая в качестве совещания Сторон Парижского соглашения, принимает правила, условия и процедуры для механизма, упомянутого в пункте 4 настоящей статьи, на своей первой сессии.

8. Стороны признают важность комплексных, целостных и сбалансированных нерыночных подходов, имеющихся в распоряжении Сторон, для оказания содействия в осуществлении их определяемых на национальном уровне вкладов в контексте устойчивого развития и искоренения нищеты скоординированным и эффективным образом, в том числе через посредство, помимо прочего, предотвращения изменения климата, адаптации, финансирования, передачи технологий и укрепления потенциала, в зависимости от обстоятельств. Эти подходы имеют целью:

a) повышение амбициозности действий по предотвращению изменения климата и адаптации;

b) расширение государственного и частного участия в осуществлении определяемых на национальном уровне вкладов; и

c) создание возможностей для координации между инструментами и соответствующими институциональными механизмами.

9. Настоящим определяются рамки для нерыночных подходов к устойчивому развитию в целях поощрения нерыночных подходов, упомянутых в пункте 8 настоящей статьи. 


\section{Статья 7}

1. Стороны настоящим учреждают глобальную цель по адаптации, заключающуюся в укреплении адаптационных возможностей, повышении сопротивляемости и снижении уязвимости к изменениям климата, в целях содействия устойчивому развитию и обеспечения адекватного адаптационного реагирования в контексте температурной цели, упомянутой в статье 2 .

2. Стороны признают, что адаптация представляет собой глобальный вызов, стоящий перед всеми в местном, субнациональном, региональном и международном измерениях, и что она является ключевым компонентом долгосрочного глобального реагирования на изменение климата в целях защиты людей, средств к существованию и экосистем и вносит вклад в такое реагирование, принимая во внимание безотлагательные и срочные потребности тех Сторон, являющихся развивающимися странами, которые являются особенно уязвимыми к неблагоприятным последствиям изменения климата.

3. Усилия по адаптации Сторон, являющихся развивающимися странами, признаются в соответствии с условиями, которые будут приняты Конференцией Сторон, действующей в качестве совещания Сторон Парижского соглашения, на ее первой сессии.

4. Стороны признают, что существующая потребность в адаптации является значительной и что более высокие уровни предотвращения изменения климата могут снизить потребности в дополнительных усилиях по адаптации, а также что более значительные потребности в адаптации могут быть сопряжены с более высокими расходами на адаптацию.

5. Стороны признают, что деятельность в области адаптации должна опираться на инициативу стран, учет гендерных аспектов, широкое участие и полностью транспарентный подход, принимая во внимание уязвимые группы, общины и экосистемы, и основываться на наилучших имеющихся научных знаниях и, в соответствующих случаях, на традиционных знаниях, знаниях коренных народов и системах местных знаний и руководствоваться ими в целях интеграции надлежащим образом действий по адаптации в соответствующие социальноэкономические и природоохранные стратегии и решения.

6. Стороны признают важность поддержки усилий по адаптации и международного сотрудничества в этой области, а также важность учета потребностей Сторон, являющихся развивающимися странами, особенно тех, которые особо уязвимы, к неблагоприятным последствиям изменения климата.

7. Стороны должны укреплять свое сотрудничество в целях активизации действий по адаптации, принимая во внимание Канкунские рамки для адаптации, в том числе в отношении:

a) обмена информацией, эффективной практикой, опытом и извлеченными уроками, в том числе, в соответствующих случаях, в отношении науки, планирования, политики и осуществления в связи с действиями по адаптации;

b) укрепления институциональных механизмов, в том числе согласно Конвенции, которые обслуживают настоящее Соглашение, для поддержки обобщения соответствующих информации и знаний и для предоставления Сторонам технической поддержки и руководящих указаний;

c) углубления научных знаний о климате, включая исследования, систематическое наблюдение климатической системы и системы раннего предупреждения, таким образом, чтобы создать информационную основу для климатических услуг и оказывать поддержку процессу принятия решений; 
d) оказания содействия Сторонам, являющимся развивающимися странами, в выявлении эффективной адаптационной практики, адаптационных потребностей, приоритетов, предоставленной и полученной поддержки для действий и усилий по адаптации, вызовов и пробелов таким образом, который согласуется с поощрением такой практики;

е) повышения эффективности и долговечности действий по адаптации.

8. К специализированным учреждениям и агентствам Организации Объединенных Наций обращается призыв поддерживать усилия Сторон по осуществлению действий, указанных в пункте 7 настоящей статьи, с учетом положений пункта 5 настоящей статьи.

9. Каждая Сторона надлежащим образом участвует в процессах планирования и осуществлении действий в области адаптации, включая разработку или укрепление соответствующих планов, политики и/или вкладов, которые могут включать:

a) осуществление действий, обещаний и/или усилий по адаптации;

b) процесс формулирования и осуществления национальных планов в области адаптации;

c) оценку воздействий изменения климата и уязвимости в целях формулирования определяемых на национальном уровне приоритетных действий, принимая во внимание потребности наиболее уязвимых людей, мест и экосистем;

d) мониторинг и оценку планов, политики, программ и действий в области адаптации и обучение на их основе; и

е) повышение сопротивляемости социально-экономических и экологических систем, в том числе путем диверсификации экономики и устойчивого управления природными ресурсами.

10. Каждая Сторона надлежащим образом должна представлять и периодически обновлять сообщение по вопросам адаптации, которое может включать ее приоритеты, потребности в осуществлении поддержки, планы и действия, без создания какого-либо дополнительного бремени для Сторон, являющихся развивающимися странами.

11. Сообщение по вопросам адаптации, упомянутое в пункте 10 настоящей статьи, в зависимости от обстоятельств, представляется и периодически обновляется в качестве компонента другого сообщения или одновременно с другим сообщением или документами, включая национальный план в области адаптации, определяемый на национальном уровне вклад, упоминаемый в статье 4, пункт 2, и/или национальное сообщение.

12. Сообщения по вопросам адаптации, упомянутые в пункте 10 настоящей статьи, регистрируются в публичном реестре, который ведется секретариатом.

13. Сторонам, являющимся развивающимися странами, предоставляется непрерывная и расширенная международная поддержка для осуществления пунктов 7, 9, 10 и 11 настоящей статьи в соответствии с положениями статей 9, 10 и 11.

14. Глобальное подведение итогов, упомянутое в статье 14, помимо прочего:

a) признает усилия по адаптации Сторон, являющихся развивающимися странами;

b) активизирует осуществление действий по адаптации с учетом сообщения по вопросам адаптации, упомянутого в пункте 10 настоящей статьи; 
с) проводит обзор адекватности и эффективности адаптации и поддержки, предоставляемой для адаптации; и

d) проводит обзор общего прогресса в достижении глобальной цели в области адаптации, упомянутой в пункте 1 настоящей статьи.

\section{Статья 8}

1. Стороны признают важность предупреждения, минимизации и решения вопросов потерь и ущерба, связанных с неблагоприятными воздействиями изменения климата, включая экстремальные погодные явления и медленно протекающие явления, а также роль устойчивого развития в снижении риска потерь и ущерба.

2. Варшавский международный механизм по потерям и ущербу в результате воздействий изменения климата функционирует под управлением и руководством Конференции Сторон, действующей в качестве совещания Сторон Парижского соглашения, и может быть расширен и укреплен по решению Конференции Сторон, действующей в качестве совещания Сторон Парижского соглашения.

3. Стороны углубляют понимание, активизируют действия и поддержку, в том числе через Варшавский международный механизм, когда это необходимо, на основе сотрудничества и стимулирования в отношении потерь и ущерба, связанных с неблагоприятными воздействиями изменения климата.

4. Таким образом, области сотрудничества и содействия по углублению понимания, активизации действий и поддержки могут включать:

а) системы раннего предупреждения;

b) готовность к чрезвычайным ситуациям;

c) медленно протекающие явления;

d) явления, которые могут приводить к необратимым и перманентным потерям и ущербу;

е) комплексную оценку и управление риском;

f) средства страхования риска, создание пулов климатических рисков и другие решения в области страхования;

g) неэкономические потери;

h) сопротивляемость общин, средств к существованию и экосистем.

5. Варшавский международный механизм сотрудничает с существующими органами и группами экспертов согласно Конвенции, а также соответствующими организациями и группами экспертов за пределами Соглашения.

\section{Статья 9}

1. Стороны, являющиеся развитыми странами, предоставляют финансовые ресурсы для оказания содействия Сторонам, являющимся развивающимися странами, в отношении как предотвращения изменения климата, так и адаптации в продолжение своих существующих обязательств по Конвенции.

2. К другим Сторонам обращается призыв предоставлять или продолжать предоставлять такую поддержку на добровольной основе. 
3. В рамках глобальных усилий Стороны, являющиеся развитыми странами, должны и впредь играть ведущую роль в мобилизации финансовых средств для предотвращения изменения климата из широкого круга источников, инструментов и каналов, отмечая значительную роль государственных фондов, посредством различных действий, включая поддержку осуществляемых по инициативе стран стратегий, а также учитывая потребности и приоритеты Сторон, являющихся развивающимися странами. Такая мобилизация финансовых средств для борьбы с изменением климата должна представлять собой продвижение вперед сверх предыдущих усилий.

4. Предоставление наращиваемых в масштабах финансовых ресурсов должно быть направлено на достижение баланса между действиями по адаптации и действиями по предотвращению изменения климата, с учетом стратегий, опирающихся на инициативу стран, а также приоритетов и потребностей Сторон, являющихся развивающими странами, прежде всего тех из них, которые особенно уязвимы к неблагоприятным последствиям изменения климата и имеют значительно ограниченный потенциал, таких как наименее развитые страны и малые островные развивающиеся государства, принимая во внимание необходимость в государственных и основанных на грантах финансовых ресурсах для адаптации.

5. Стороны, являющиеся развитыми странами, будут сообщать на двухгодичной основе ориентировочную количественную и качественную информацию, относящуюся к пунктам 1 и 3 настоящей статьи, когда это необходимо, включая прогнозируемые уровни государственных финансовых ресурсов, при наличии таковых, которые будут предоставлены Сторонам, являющимся развивающимися странами. К другим предоставляющим ресурсы Сторонам обращается призыв сообщать такую информацию раз в два года на добровольной основе.

6. В ходе глобального подведения итогов, упомянутого в статье 14, будет учитываться соответствующая информация, представленная Сторонами, являющимися развитыми странами, и/или органами Соглашения, об усилиях, касающихся финансовых средств для борьбы с изменением климата.

7. Стороны, являющиеся развитыми странами, представляют транспарентную и согласованную информацию о поддержке для Сторон, являющихся развивающимися странами, которая предоставляется и мобилизуется при помощи государственного вмешательства, на двухгодичной основе в соответствии с условиями, процедурами и руководящими принципами, которые будут приняты Конференцией Сторон, действующей в качестве совещания Сторон Парижского соглашения, на ее первой сессии, как это предусмотрено в статье 13 , пункт 13 . К другим Сторонам обращается призыв сделать то же.

8. Финансовый механизм Конвенции, включая его оперативные органы, выполняет функции финансового механизма настоящего Соглашения.

9. Учреждения, обслуживающие настоящее Соглашение, включая оперативные органы Финансового механизма Конвенции, стремятся обеспечить Сторонам, являющимся развивающимися странами, эффективный доступ к финансовым ресурсам посредством упрощенных процедур одобрения и расширения поддержки в деле обеспечения готовности для Сторон, являющихся развивающимися странами, в частности для наименее развитых стран и малых островных развивающихся государств, в контексте их национальных стратегий и планов в области борьбы с изменением климата. 


\section{Статья 10}

1. Стороны разделяют долгосрочное видение важности полной реализации разработки и передачи технологий в целях повышения сопротивляемости к изменению климата и сокращения выбросов парниковых газов.

2. Стороны, отмечая важность технологий для осуществления действий по предотвращению изменения климата и адаптации согласно настоящему Соглашению и признавая существующие усилия по внедрению и распространению технологий, укрепляют действия по сотрудничеству в области разработки и передачи технологий.

3. Механизм по технологиям, учрежденный согласно Конвенции, обслуживает настоящее Соглашение.

4. Настоящим учреждаются рамки по вопросам технологий для обеспечения всеобъемлющего руководства работой Механизма по технологиям в деле поощрения и облегчения более активных действий по разработке и передаче технологий в целях поддержки осуществления настоящего Соглашения в интересах реализации долгосрочного видения, о котором говорится в пункте 1 настоящей статьи.

5. Ускорение и поощрение инноваций и создание для них благоприятных условий имеют огромное значение для эффективного, долгосрочного глобального реагирования на изменение климата и для поощрения экономического роста и устойчивого развития. Такие усилия получают надлежащую поддержку, в том числе со стороны Механизма по технологиям и за счет финансовых средств Финансового механизма Конвенции, для выработки совместных подходов к исследованиям и разработкам, а также расширения доступа к технологиям, в частности на ранних этапах технологического цикла, для Сторон, являющихся развивающимися странами.

6. Сторонам, являющимся развивающимися странами, предоставляется поддержка, включая финансовую поддержку, для осуществления настоящей статьи, в том числе для укрепления совместных действий в области разработки и передачи технологий на различных этапах технологического цикла, с целью обеспечения баланса между поддержкой предотвращения изменения климата и поддержкой адаптации. В ходе глобального подведения итогов, упомянутого в статье 14 , учитывается имеющаяся информация об усилиях, касающихся поддержки в области разработки и передачи технологий Сторонам, являющимся развивающимися странами.

\section{Статья 11}

1. Укрепление потенциала согласно настоящему Соглашению должно укреплять возможности и способности Сторон, являющихся развивающими странами, в особенности стран с наименьшими возможностями, таких как наименее развитые страны и страны, особенно уязвимые к неблагоприятным воздействиям изменения климата, таких как малые островные развивающиеся государства, осуществлять эффективные действия по борьбе с изменением климата, в том числе, помимо прочего, осуществлять действия по адаптации и предотвращению изменения климата, а также должно облегчать разработку, распространение и внедрение технологий и доступ к финансированию борьбы с изменением климата, содействовать соответствующим аспектам просвещения, подготовки кадров и информирования общественности и облегчать транспарентное, своевременное и точное сообщение информации. 
2. Укрепление потенциала должно осуществляться по инициативе стран, базироваться на национальных потребностях и реагировать на них, а также укреплять сопричастность стран, особенно Сторон, являющихся развивающимися странами, в том числе на национальном, субнациональном и местном уровне. Укрепление потенциала должно руководствоваться извлеченными уроками, в том числе уроками, извлеченными в ходе деятельности по укреплению потенциала согласно Конвенции, и оно должно представлять собой эффективный, цикличный процесс, который базируется на широком участии, имеет сквозной характер и учитывает гендерные аспекты.

3. Все Стороны должны сотрудничать в укреплении потенциала Сторон, являющихся развивающимися странами, в области осуществления настоящего Соглашения. Стороны, являющиеся развитыми странами, должны увеличивать поддержку для действий в целях укрепления потенциала в Сторонах, являющихся развивающимися странами.

4. Все Стороны, укрепляющие потенциал Сторон, являющихся развивающимися странами, для выполнения настоящего Соглашения, в том числе на основе региональных, двусторонних и многосторонних подходов, регулярно сообщают об этих действиях или мерах по укреплению потенциала. Стороны, являющиеся развивающимися странами, должны регулярно сообщать о прогрессе, достигнутом в осуществлении планов, политики, действий или мер по осуществлению настоящего Соглашения.

5. Деятельность по укреплению потенциала активизируется при помощи надлежащих институциональных механизмов для оказания поддержки осуществлению настоящего Соглашения, включая надлежащие институциональные механизмы, учрежденные согласно Конвенции, которые обслуживают настоящее Соглашение. Конференция Сторон, действующая в качестве совещания Сторон Парижского соглашения, на своей первой сессии рассматривает и принимает решение о первоначальных институциональных механизмах для укрепления потенциала.

\section{Статья 12}

Стороны сотрудничают в осуществлении надлежащим образом мер по активизации просвещения, подготовки кадров, информирования общественности, участия общественности и доступа общественности к информации по вопросам изменения климата, признавая важность этих шагов для активизации действий согласно настоящему Соглашению.

\section{Статья 13}

1. В целях укрепления взаимного доверия и уверенности и содействия эффективному осуществлению настоящим учреждаются расширенные рамки для обеспечения транспарентности действий и поддержки, предусматривающие гибкость, учитывающие различные возможности Сторон и опирающиеся на коллективный опыт.

2. Рамки для обеспечения транспарентности предусматривают гибкость при осуществлении положений настоящей статьи для тех Сторон, являющихся развивающимися странами, которым это необходимо в свете их возможностей. Условия, процедуры и руководящие принципы, упомянутые в пункте 13 настоящей статьи, отражают такую гибкость. 
3. Рамки для обеспечения транспарентности используют и активизируют механизмы обеспечения транспарентности согласно Конвенции, признавая особые условия наименее развитых стран и малых островных развивающихся государств, и осуществляются стимулирующим, неинтрузивным, ненаказательным способом при уважении национального суверенитета и при недопущении возложения чрезмерного бремени на Стороны.

4. Механизмы обеспечения транспарентности согласно Конвенции, включая национальные сообщения, двухгодичные доклады и двухгодичные доклады, содержащие обновленную информацию, международные оценку и обзор и международные консультации и анализ, составляют часть опыта, используемого для разработки условий и процедур и руководящих указаний согласно пункту 13 настоящей статьи.

5. Цель рамок для обеспечения транспарентности действий заключается в обеспечении ясного понимания действий по борьбе с изменением климата в свете цели Конвенции, как она изложена в ее статье 2, включая обеспечение ясности и отслеживание прогресса в достижении индивидуальных определяемых на национальном уровне вкладов Сторон согласно статье 4; и действий Сторон по адаптации согласно статье 7, включая эффективные практику, приоритеты, потребности и пробелы, в целях создания информационной основы для глобального подведения итогов согласно статье 14.

6. Цель рамок для обеспечения транспарентности поддержки заключается в обеспечении ясного понимания поддержки, которую предоставляют и получают соответствующие индивидуальные Стороны в контексте действий по борьбе с изменением климата согласно статьям 4, 7, 9, 10 и 11, и формировании, насколько это возможно, общей картины предоставляемой совокупной финансовой поддержки в целях создания информационной основы для глобального подведения итогов согласно статье 14 .

7. Каждая Сторона регулярно представляет следующую информацию:

a) информацию в отношении национального кадастра антропогенных выбросов из источников и абсорбции поглотителями парниковых газов, составляемого с использованием методологий на основе надлежащей практики, принятых Межправительственной группой экспертов по изменению климата и согласованных Конференцией Сторон, действующей в качестве совещания Сторон Парижского соглашения;

b) информацию, необходимую для отслеживания прогресса в осуществлении и достижении ее определяемых на национальном уровне вкладов согласно статье 4 .

8. Каждая Сторона должна также в надлежащих случаях представлять информацию в отношении воздействий изменения климата и адаптации согласно статье 7.

9. Стороны, являющиеся развитыми странами, должны представлять, а другим Сторонам следует представлять информацию о финансовой поддержке, поддержке в области передачи технологий и поддержки в области укрепления потенциала, предоставляемой Сторонам, являющимся развивающимися странами, согласно статьям 9, 10 и 11.

10. Сторонам, являющимся развивающимися странами, следует представлять информацию о финансовой поддержке, поддержке в области передачи технологий и поддержке в области укреплении потенциала, необходимой и полученной согласно статьям 9, 10 и 11. 
11. Информация, представленная каждой Стороной согласно пунктам 7 и 9 настоящей статьи, подлежит рассмотрению техническими экспертами в соответствии с решением 1/CР.21. Для тех Сторон, являющихся развивающимися странами, которые нуждаются в этом в свете их возможностей, процесс рассмотрения включает предоставление помощи в выявлении потребностей в области укрепления потенциала. Кроме того, каждая Сторона принимает участие в стимулирующем, многостороннем рассмотрении прогресса в отношении усилий согласно статье 9 и соответствующего осуществления и достижения ею ее определяемого на национальном уровне вклада.

12. Рассмотрение техническими экспертами согласно настоящему пункту включает в себя рассмотрение предоставленной Стороной поддержки, в соответствующих случаях, а также осуществления и достижения ею ее определяемых на национальном уровне вкладов. Рассмотрение также определяет области, требующие улучшений, для этой Стороны и включает рассмотрение соответствия информации условиям, процедурам и руководящим указаниям, упомянутым в пункте 13 настоящей статьи, с учетом гибкости, предоставляемой Стороне согласно пункту 2 настоящей статьи. При рассмотрении особое внимание уделяется соответствующим национальным возможностям и обстоятельствам Сторон, являющихся развивающимися странами.

13. Конференция Сторон, действующая в качестве совещания Сторон Парижского соглашения, на своей первой сессии, на основе опыта работы механизмов, связанных с транспарентностью согласно Конвенции, и опираясь на положения настоящей статьи, принимает надлежащие общие условия, процедуры и руководящие принципы обеспечения транспарентности действий и поддержки.

14. Развивающимся странам предоставляется поддержка для осуществления настоящей статьи.

15. Сторонам, являющимся развивающимися странами также на непрерывной основе предоставляется поддержка для укрепления потенциала, связанного с транспарентностью.

\section{Статья 14}

1. Конференция Сторон, действующая в качестве совещания Сторон Парижского соглашения, периодически подводит итоги осуществления настоящего Соглашения для оценки коллективного прогресса в выполнении задачи настоящего Соглашения и в достижении его долгосрочных целей (именуется как «глобальное поведение итогов»). Она делает это всеобъемлющим и стимулирующим образом, рассматривая предотвращение изменения климата, адаптацию и средства осуществления и поддержки, и в свете справедливости и наилучших имеющихся научных знаний.

2. Конференция Сторон, действующая в качестве совещания Сторон Парижского соглашения, проводит первое глобальное подведение итогов в 2023 году и впоследствии каждые пять лет, если Конференция Сторон, действующая в качестве совещания Сторон Парижского соглашения, не примет иного решения.

3. Результаты глобального подведения итогов служат информационной основой для Сторон при обновлении и активизации их определяемых на национальном уровне действий и поддержки согласно соответствующим положениям настоящего Соглашения, а также при активизации международного сотрудничества для действий по борьбе с изменением климата. 


\section{Статья 15}

1. Настоящим учреждается механизм для содействия осуществлению и поощрения соблюдения положений настоящего Соглашения.

2. Механизм, упомянутый в пункте 1 настоящей статьи, состоит из комитета, который основывается на знаниях экспертов и имеет стимулирующий характер и который функционирует транспарентным, невраждебным и ненаказательным образом. Комитет уделяет особое внимание соответствующим национальным возможностям и обстоятельствам Сторон.

3. Комитет функционирует в соответствии с условиями и процедурами, принятыми Конференцией Сторон, действующей в качестве совещания Сторон Парижского соглашения, на ее первой сессии, и ежегодно представляет доклады Конференции Сторон, действующей в качестве совещания Сторон Парижского соглашения.

\section{Статья 16}

1. Конференция Сторон, высший орган Конвенции, действует в качестве совещания Сторон настоящего Соглашения.

2. Стороны Конвенции, которые не являются Сторонами настоящего Соглашения, могут участвовать в качестве наблюдателей в работе любой сессии Конференции Сторон, действующей в качестве совещания Сторон настоящего Соглашения. Когда Конференция Сторон действует в качестве совещания Сторон настоящего Соглашения, решения согласно настоящему Соглашению принимаются только теми из них, которые являются Сторонами настоящего Соглашения.

3. Когда Конференция Сторон действует в качестве совещания Сторон настоящего Соглашения, любой член Президиума Конференции Сторон, представляющий Сторону Конвенции, которая на данный момент не является Стороной настоящего Соглашения, замещается дополнительным членом, который избирается Сторонами настоящего Соглашения из их числа.

4. Конференция Сторон, действующая в качестве совещания Сторон Парижского соглашения, регулярно проводит обзор осуществления настоящего Соглашения и принимает в рамках своего мандата решения, необходимые для поощрения его эффективного осуществления. Она выполняет функции, порученные ей согласно настоящему Соглашению, и:

a) учреждает такие вспомогательные органы, которые она считает необходимыми для осуществления настоящего Соглашения; и

b) выполняет такие другие функции, которые могут потребоваться для осуществления настоящего Соглашения.

5. Правила процедуры Конференции Сторон и финансовые процедуры, используемые согласно Конвенции, применяются к настоящему Соглашению mutatis mutandis, за исключением тех случаев, когда Конференция Сторон, действующая в качестве совещания Сторон Парижского соглашения, может на основе консенсуса принять иное решение.

6. Секретариат созывает первую сессию Конференции Сторон, действующей в качестве совещания Сторон Парижского соглашения, одновременно с первой сессией Конференции Сторон, которая запланирована после даты вступления в силу настоящего Соглашения. Последующие очередные сессии Конференции Сторон, действующей в качестве совещания Сторон Парижского соглашения, проводятся одновременно с очередными сессиями Конференции Сторон, если Конференция 
Сторон, действующая в качестве совещания Сторон Парижского соглашения, не примет иного решения.

7. Внеочередные сессии Конференции Сторон, действующей в качестве совещания Сторон Парижского соглашения, созываются, когда Конференция Сторон, действующая в качестве совещания Сторон Парижского соглашения, сочтет это необходимым, или по письменному требованию любой из Сторон, при условии, что в течение шести месяцев после того, как секретариат направит это требование Сторонам, оно будет поддержано не менее чем одной третью Сторон.

8. Организация Объединенных Наций и ее специализированные учреждения и Международное агентство по атомной энергии, а также любое государствочлен таких организаций или наблюдатели при них, которые не являются Сторонами Конвенции, могут быть представлены на сессиях Конференции Сторон, действующей в качестве совещания Сторон Парижского соглашения, в качестве наблюдателей. Любые органы или учреждения, будь то национальные или международные, правительственные или неправительственные, которые обладают компетенцией в вопросах, относящихся к сфере действия настоящего Соглашения, и которые сообщили секретариату о своем желании быть представленными на сессии Конференции Сторон, действующей в качестве совещания Сторон Парижского соглашения, в качестве наблюдателя, могут быть допущены к участию в ней, за исключением тех случаев, когда против этого возражают не менее одной трети присутствующих Сторон. Допуск и участие наблюдателей регулируются правилами процедуры, как это предусмотрено в пункте 5 настоящей статьи.

\section{Статья 17}

1. Секретариат, учрежденный в соответствии со статьей 8 Конвенции, действует в качестве секретариата настоящего Соглашения.

2. Статья 8, пункт 2, Конвенции о функциях секретариата и статья 8, пункт 3, Конвенции об организации функционирования секретариата применяются к настоящему Соглашению mutatis mutandis. Кроме того, секретариат выполняет функции, возложенные на него согласно настоящему Соглашению и Конференцией Сторон, действующей в качестве совещания Сторон Парижского соглашения.

\section{Статья 18}

1. Вспомогательный орган для консультирования по научным и техническим аспектам и Вспомогательный орган по осуществлению, учрежденные в соответствии со статьями 9 и 10 Конвенции, действуют соответственно в качестве Вспомогательного органа для консультирования по научным и техническим аспектам и Вспомогательного органа по осуществлению настоящего Соглашения. Положения, касающиеся функционирования этих двух органов в соответствии с Конвенцией, применяются к настоящему Соглашению mutatis mutandis. Сессии заседаний Вспомогательного органа для консультирования по научным и техническим аспектам и Вспомогательного органа по осуществлению настоящего Соглашения проводятся соответственно в связи с заседаниями Вспомогательного органа для консультирования по научным и техническим аспектам и Вспомогательного органа по осуществлению Конвенции.

2. Стороны Конвенции, которые не являются Сторонами настоящего Соглашения, могут участвовать в качестве наблюдателей в работе любой сессии вспомогательных органов. Когда вспомогательные органы действуют в качестве вспомогательных органов настоящего Соглашения, решения в отношении настоящего Со- 
глашения принимаются лишь теми Сторонами, которые являются Сторонами настоящего Соглашения.

3. Когда вспомогательные органы, учрежденные в соответствии со статьями 9 и 10 Конвенции, выполняют свои функции в отношении вопросов, касающихся настоящего Соглашения, любой член бюро этих вспомогательных органов, представляющий Сторону Конвенции, которая в данный момент не является Стороной настоящего Соглашения, замещается дополнительным членом, который избирается Сторонами настоящего Соглашения из их числа.

\section{Статья 19}

1. Вспомогательные органы или любые другие институциональные процедуры, учрежденные Конвенцией или согласно Конвенции, помимо тех вспомогательных органов и институциональных механизмов, которые упомянуты в настоящем Соглашении, обслуживают настоящее Соглашение согласно решению Конференции Сторон, действующей в качестве совещания Сторон Парижского соглашения . Конференция Сторон, действующая в качестве совещания Сторон Парижского соглашения, определяет функции, которые будут выполнять такие вспомогательные органы или механизмы.

2. Конференция Сторон, действующая в качестве совещания Сторон Парижского соглашения, может давать таким вспомогательным органам и институциональным механизмам дальнейшие руководящие указания.

\section{Статья 20}

1. Настоящее Соглашение открыто для подписания и подлежит ратификации, принятию или одобрению государствами и региональными организациями экономической интеграции, которые являются Сторонами Конвенции. Оно открыто для подписания в Центральных учреждениях Организации Объединенных Наций в Нью-Йорке с 22 апреля 2016 года до 21 апреля 2017 года. Настоящее Соглашение открывается для присоединения на следующий день после даты его закрытия для подписания. Документы о ратификации, принятии, одобрении или присоединении сдаются на хранение Депозитарию.

2. Любая региональная организация экономической интеграции, которая становится Стороной настоящего Соглашения, но при этом ни одно из ее государств-членов не является Стороной, несет все обязательства, вытекающие из настоящего Соглашения. В случае региональных организаций экономической интеграции, у которых одно или несколько государств-членов являются Сторонами настоящего Соглашения, данная организация и ее государства-члены принимают решения в отношении своих соответствующих обязанностей по выполнению ими взятых на себя обязательств по настоящему Соглашению. В таких случаях данная организация и ее государства-члены не могут параллельно осуществлять права, вытекающие из настоящего Соглашения.

3. В своих документах о ратификации, принятии, одобрении или присоединении региональные организации экономической интеграции объявляют о пределах своей компетенции в отношении вопросов, регулируемых настоящим Соглашением. Эти организации также информируют Депозитария, который, в свою очередь, информирует Стороны, о любых существенных изменениях в пределах их компетенции. 


\section{Статья 21}

1. Настоящее Соглашение вступает в силу на тридцатый день после того, как не менее 55 Сторон Конвенции, на долю которых, по оценкам, приходится в совокупности как минимум 55\% общих глобальных выбросов парниковых газов, сдадут на хранение свои документы о ратификации, принятии, одобрении или присоединении.

2. Исключительно для ограниченной цели пункта 1 настоящей статьи «общие глобальные выбросы парниковых газов» означают самое последнее количество, сообщенное на дату или до даты принятия настоящего Соглашения Сторонами Конвенции.

3. Для каждого государства или региональной организации экономической интеграции, которые ратифицируют, принимают или одобряют настоящее Соглашение или присоединяются к нему после выполнения условий, изложенных в пункте 1 настоящей статьи для вступления в силу, настоящее Соглашение вступает в силу на тридцатый день после сдачи на хранение таким государством или такой региональной организацией экономической интеграции их документов о ратификации, принятии, одобрении или присоединении.

4. Для целей пункта 1 настоящей статьи ни один документ, сданный на хранение региональной организацией экономической интеграции, не засчитывается в качестве дополнительного к документам, сданным на хранение ее государствамичленами.

\section{Статья 22}

Положения статьи 15 Конвенции о принятии поправок к Конвенции применяются к настоящему Соглашению mutatis mutandis.

\section{Статья 23}

1. Положения статьи 16 Конвенции о принятии приложений и о принятии поправок к приложениям к Конвенции применяются к настоящему Соглашению mutatis mutandis.

2. Приложения к настоящему Соглашению составляют его неотьемлемую часть, и, если прямо не предусматривается иного, ссылка на настоящее Соглашение представляет собой в то же время ссылку на любые приложения к нему. Такие приложения ограничиваются перечнями, формами или любыми другими материалами описательного характера, которые касаются научных, технических, процедурных или административных вопросов.

\section{Статья 24}

Положения статьи 14 Конвенции об урегулировании споров применяются к настоящему Соглашению mutatis mutandis.

\section{Статья 25}

1. Каждая Сторона имеет один голос, за исключением случаев, предусмотренных в пункте 2 настоящей статьи. 
2. Региональные организации экономической интеграции в вопросах, относящихся к их компетенции, осуществляют свое право на голосование с количеством голосов, равным количеству их государств-членов, которые являются Сторонами настоящего Соглашения. Такая организация не использует свое право на голосование, если какое-либо из ее государств-членов осуществляет свое право и наоборот.

\section{Статья 26}

Депозитарием настоящего Соглашения является Генеральный секретарь Организации Объединенных Наций.

\section{Статья 27}

Оговорки к настоящему Соглашению не допускаются.

\section{Статья 28}

1. В любое время по истечении трех лет с даты вступления настоящего Соглашения в силу для той или иной Стороны эта Сторона может выйти из настоящего Соглашения, направив письменное уведомление Депозитарию.

2. Любой такой выход вступает в силу по истечении одного года с даты получения Депозитарием уведомления о выходе или в такой более поздний срок, который может быть указан в уведомлении о выходе.

3. Любая Сторона, которая выходит из Конвенции, считается также вышедшей из настоящего Соглашения.

\section{Статья 29}

Подлинник настоящего Соглашения, тексты которого на английском, арабском, испанском, китайском, русском и французском языках являются равно аутентичными, сдается на хранение Генеральному секретарю Организации Объединенных Наций.

СОВЕРШЕНО в Париже двенадцатого дня декабря месяца две тысячи пятнадцатого года.

В УДОСТОВЕРЕНИЕ ЧЕГО нижеподписавшиеся, должным образом на то уполномоченные, поставили свои подписи под настоящим Соглашением. 